\title{
Is gold a hedge or safe haven against oil and currency market movements? A revisit using multifractal approach
}

\author{
Mohamed Arbi Madani ${ }^{1}$ (D) Zied Ftiti ${ }^{2}$
}

Accepted: 22 September 2021 / Published online: 4 November 2021

(c) The Author(s), under exclusive licence to Springer Science+Business Media, LLC, part of Springer Nature 2021

\begin{abstract}
We investigate gold's role as a hedge or safe haven against oil price and currency movements across calm and extreme market conditions. For the empirical analysis, we extend the intraday multifractal correlation measure developed by Madani et al. (Bankers, Markets \& Investors, 163:2-13, 2020) to consider the dependence for calm and extreme movement periods across different time scales. Interestingly, we employ the rolling window method to examine the time-varying dependence between gold-oil and gold-currency in terms of calm and turmoil market conditions. Based on high frequency (5-min intervals) across the period 2017-2019, our analysis shows three interesting findings. First, gold acts as a weak (strong) hedge for oil (currency) market movements, across all agent types. Second, gold has strong safe-haven capability against extreme currency movements, and against only short time scales of oil price movements. Third, hedging strategies confirm the scale-dependent gold's role in reducing portfolio risk as a hedge or safe haven. Implications for investors, financial institutions, and policymakers are discussed.
\end{abstract}

Keywords Hedge ratio $\cdot$ Intraday $\cdot$ Multifractal $\cdot$ Non-linearity $\cdot$ Optimal portfolio $\cdot$ Time scale

\section{Introduction}

To understand economic complexity, it is necessary to consider the comprehensive dynamics of different markets, and particularly, the nature of their interactions. Underlying market interactions remain a great challenge for successful portfolio management, especially with the occurrence of several turmoil periods in a short timeframe. ${ }^{1}$ Thus, lessons from market

\footnotetext{
${ }^{1}$ Since 2000 , several periods of turmoil have occurred, including the dot-com bubble, financialization of commodity markets, the US housing boom, the subprime crisis, the sovereign debt crisis, and an environment of increased uncertainty, COVID-19 crisis.
}

$\bowtie \quad$ Mohamed Arbi Madani

madanimedarbi@gmail.com

Zied Ftiti

Zied.Ftiti@edcparis.edu

1 University of Tunis, ISG-T, LR GEF-2A, 41 Ave de la Liberte, 2000 Tunis, Tunisia

2 EDC Paris Business School, 70 Galerie des Damiers, La défense 1, 92415 Paris, France 
interactions would be useful for asset allocation optimization, portfolio diversification, and hedging strategies (Markowitz, 1952; Plerou et al., 2002).

Galton (1886) pioneered the development of the theoretical concept of connections between time series. Pearson (1895) defined the Galton correlation coefficient with the aim of measuring the similarity of price changes between pairs of assets, which came to be known as the Pearson correlation coefficient. ${ }^{2}$ Several measures have been developed to measure the cross-correlation between time series and especially since the 1980s, there has been a revolution in econometric theory. Most of this research deals with linear models and stationary time-series (e.g., Engle \& Granger, 1987, 1991). Some studies deal with time-varying connection and extended correlation matrix in different ways in order to extract useful information for understanding time-varying financial market dependence (Bollerslev et al., 1988; Campbell et al., 2008; Forbes \& Rigobon, 2002; Huang et al., 2013; Krishan et al., 2009). In the last decade, a new strand of literature has emerged to highlight the complexity of the behavior of financial series, especially after the occurrence of various turmoil periods in a short timeframe (since 2000). Interestingly, these studies point out the high degree of the non-stationary behavior of financial series, indicating self-affinity behavior, which may characterize cross-correlation by power laws (Wạtorek et al., 2019).

This study is related to this last strand of literature, specifically, the multifractal approach used for portfolio management. As diversification benefits occur more during times of greater volatility in financial markets (Ang \& Bekaert, 2002), we propose a new measure of crosscorrelation for different order of moments (second and fourth, in particular). In other words, we propose a new cross-correlation that is useful for measuring classical dependence (second moment) and cross-correlation for extreme movement (fourth moment). Interestingly, to the best of our knowledge, no research has used this kind of approach to provide further information about the role of gold as hedge and safe-haven asset against oil and US currency movements. From an econometric theory point of view, several techniques have been developed to investigate the fractal and the multifractal properties in time series. Some approaches are employed for the univariate case, analyzing the auto-correlation of a time series, such as the detrended fluctuation analysis of Peng et al. (1995) and the detrending moving average (DMA) analysis of Vandewalle and Ausloos (1998). Multifractal versions have also been proposed, namely, multifractal detrended fluctuation analysis and multifractal detrending moving average (MFDMA) by Gu and Zhou (2010). Recently, some studies have shown interest in power-law cross-correlation. Podobnik and Stanley (2008) proposed detrended crosscorrelation analysis (DCCA) to investigate power-law cross correlations between different, but simultaneously recorded time series in the presence of non-stationarity. Zebende (2011) and Kristoufek (2014b) proposed scale-specific correlation coefficients based on DCCA and DMCA, respectively, analogous to the Pearson coefficient. ${ }^{3}$ The DMCA method is considered an improvement over the DCCA approach, as it avoids a box-splitting procedure and assumes a power-law scaling of covariances with increasing moving average window size. However, the abovementioned methods measure the cross-correlations only for the second moment. In this work, we introduce a variant of the q-DCCA coefficient (Kwapień et al., 2015) and an extension of the DMCA coefficient, termed the q-detrending moving average cross-correlation (q-DMCA) coefficient, which is used to quantify the strength of crosscorrelations on different temporal scales and amplitudes between two non-stationary time

\footnotetext{
2 The Pearson correlation coefficient has been interpreted in different ways for analysis of the connection between time series. For details, see Rodgers and Nicewander (1988).

${ }^{3}$ Similarly, the variance is presented by the detrended fluctuation function $\left(F_{D F A}^{2}\right.$ or $\left.F_{D M A}^{2}\right)$ and the covariance is presented by the detrended covariance function $\left(F_{D C C A}^{2}\right.$ or $\left.F_{D M C A}^{2}\right)$.
} 
series. From a theoretical point of view, most previous studies have investigated gold's role as a safe haven for stock market movements and oil price changes (Baur \& Lucey, 2010; Beckmann et al., 2015; Ftiti et al., 2016; Miyazaki et al., 2012; Nguyen et al., 2016, 2020; Sephton \& Mann, 2018; Tiwari et al., 2020) while others have considered gold as a hedge against inflation (Beckmann et al., 2019; Blose, 2010; Hoang et al., 2016; Lucey et al., 2017; Tully \& Lucey, 2007; Wang et al., 2011). Few studies have focused on the role of gold as a hedge or investment safe haven against currency depreciation (Baur \& McDermott, 2016; Iqbal, 2017; Joy, 2011; Reboredo, 2013; Reboredo \& Rivera-Castro, 2014a). Our analysis fills this gap in the literature by dealing with intraday gold's role against movements in oil and currency markets, which is useful for asset allocation and hedging strategies for various reasons. Interestingly, recent oil price movements have not been driven by market supply-demand forces, but rather by US exchange rate fluctuations, as the US dollar (USD) is a major invoicing currency. When the USD depreciates, investors tend to hold gold as a hedge against currency movements and as a safe-haven asset against extreme currency movements. Empirically, our study contributes to the literature in several ways. First, we develop a new cross-correlation coefficient offering the advantage of considering investors' heterogeneity across calm and turmoil market conditions. Second, we propose an empirical framework based on an intraday dataset useful in today's modern financial markets, as high frequencies offer more information and realistic design, especially with respect to market practitioners' perspective in term of risk management and hedging.

Based on the intraday data, ranged from May 2017 to March 2019 (the sample includes 35,608 observations), for main currency markets forming the US DXY aggregate index, giving the main US trend, oil prices, and gold prices, we develop a new multifractal cross-correlation measure-the q-detrending moving average cross-correlation coefficien$\mathrm{t}$-investigating the hedging and/or safe-haven role of the gold market. Then, we test the performance of this new measure compared to the q-DCCA coefficient developed by Kwapien et al. (2015), dealing similarly with cross-correlation for different order of moments. Based on the numerical experiment, in line with Kristoufek (2017), we confirm the superiority of our measure for large samples (as is the case of an intraday dataset). Finally, the estimation results are used to test the significant role of gold as a hedge and safe haven against oil and USD depreciation at different time scales by estimating the optimal portfolio weights and the optimal hedge ratio. The results between gold and USD exchange rates support the role of gold as an effective hedge and safe-haven asset. Regarding oil and gold, the results show independence for all time scales for moment of order two, supporting the weak hedge of gold against oil. However, for turmoil periods, the relationship is negative for a time scale of less than 600 (less than 1 week of trade), providing evidence of gold as a safe haven against oil in the short run. Furthermore, our time-varying measure allows us to conclude that the power of gold's role as hedge and safe haven against oil and US currency markets is not stable and change over time.

The subsequent part of this study is presented as follows. Section 2, briefly reviews the literature. Sections 3 and 4 present the developed q-DMCA measure of cross-correlation and its validation based on numerical experiments, respectively. Section 5 discusses the results and Sect. 6 concludes.

\section{Literature review}

There are only a few studies dealing with gold as a hedge and/or a safe haven against currency depreciation and they are quite recent. However, this literature may be related to earlier studies 
on the linear connection between gold and the USD and those investigating the connection between gold and oil.

Beckers \& Soenen (1984) investigated gold's holding positions for US and non-US investors, and showed a negative correlation between the return on gold investments (in USD) and the strength of the USD on the foreign exchange market as well as asymmetric risk diversification with advantage for non-US investors. Sjaastad \& Scacciavillani (1996) and Sjaastad (2008) concluded that the appreciation or depreciation of the USD has significant effects on the gold price by using the forecast error approach.

Moreover, another strand of research has found strong relationships between gold and oil prices (Ye, 2007; Zhang et al., 2007). Using GARCH family models, Hammoudeh \& Yuan (2008) examined the volatility behavior of three metals, gold, silver, and copper, and found that oil stocks do not impact all three metals in the same way. Other studies support a long-term relationship between oil and gold prices (Bouri et al., 2017; Narayan et al., 2010).

Few studies have examined the hedging and/or safe-haven capability of gold against currencies. Joy (2011) investigated the role of gold as a safe haven and/or hedge against currency depreciation. Based on the DCCA-GARCH model, he indicated that gold is a weak safe haven and a successful hedge against the USD. Chang et al. (2013) investigated the correlation among oil prices, gold prices, and the new Taiwan dollar versus the USD exchange rate by employing several linear tests and models (Johansen co-integration test, Granger causality test, vector autoregression model, impulse response analysis, and variance decomposition method). The authors concluded that the variables are considerably independent. Previous studies have imposed some strong assumptions that do not match the specificities of financial and commodities markets, which have been characterized by chaotic structural change since the stock market crash of October 19, 1987 (Hsieh, 1991). In fact, financial globalization since the 1980s and dynamic patterns in the global economy have been caused by developments in information-processing technologies and the more global nature of all economic activity. There was rapid expansion of international financial activity, continuing at least to a peak in 2006 of "the long boom" (the Joseph effect) that preceded the global financial crisis in December 2008 (the Noé effect), generating 6 trillion USD or approximately 20\\% of world GDP. To specify these more general mean structures in gold price, oil price, and exchange rate relationships, many authors have employed non-linear models. By applying the structural break cointegration test, Narayan et al. (2010) confirmed the existence of structural break cointegration between these markets. Reboredo (2013) used copulas to characterize average and extreme market dependence between gold and the USD; the empirical results suggest that gold can act as a hedge and safe haven against USD depreciation. Kanjilal \& Ghosh (2017) employed threshold cointegration to find a non-linear relationship between gold and oil prices. The non-linear ARDL model was also employed by Kumar (2017) to underline the importance of asymmetric co-movement between gold and oil markets. Reboredo and Rivera-Castro (2014b) and Baruník et al. (2016) examined gold-exchange rate and gold-oil relationships, respectively, from a perspective of different investment horizons using the wavelet approach. Recently, Tiwari et al. (2020) used a Markov-switching time-varying copula model and multi-resolution analysis (MRA) to examine the dependence structure and dynamics between gold and oil prices.

The above-mentioned literature has investigated gold's role as a hedge or safe haven against oil price and/or currency movements. However, this literature does not distinguish between the roles of gold during calm versus turmoil periods. This study aims to fill this gap by proposing a new empirical correlation measure based on the intraday multifractal method. This new measure has at least two advantages. First, we propose an intraday measure to gain more insights on the co-dynamics of the studied markets and explore the existence of 
evolving short-range predictability. Second, the multifractal approach considers the investors' heterogeneity. In addition, all the studies mentioned above used data with a daily frequency, but the actual flow of data is defined tick by tick, at each quote and each transaction. More specifically, as gold and oil futures are among the most traded commodities, investors can set a sufficiently narrow window of time around each announcement of a sudden event or monetary policy to verify whether the markets are impacted by a specific news.

\section{Empirical design}

\subsection{The generalization of the DMCA}

We can use the information provided by the detrending cross-correlation moving average analysis to distinguish between hedge and safe-haven properties which measure dependence between two or more variables in terms of average movements by the second order $(q=2)$ and in terms of extreme market movements by the fourth order $(q=4)$. According to the definitional approach described in Kaul \& Sapp (2006), Baur \& Lucey (2010), and Baur \& McDermott (2010), the distinctive features of an asset as a hedge or safe haven are as follows.

- An asset is a weak (or strong) hedge if it is uncorrelated (or negatively correlated) with another asset or portfolio on average.

- An asset is a weak (or strong) safe haven if it is uncorrelated (or negatively correlated) with another asset or portfolio in times of extreme market movements.

The DMCA coefficient can be regarded as an alternative and a complement to the DCCA coefficient (Kristoufek, 2014b). According to the results of Kristoufek (2014a) and Sun and Liu (2016), the DCCA coefficient proposed by Zebende (2011) dominates the Pearson coefficient. Thereafter, Kristoufek (2014b) proposed the DMCA coefficient and found that it can be regarded as both an alternative and a complement to the DCCA coefficient. This new measure is based on the DMA (Alessio et al., 2002; Vandewalle \& Ausloos, 1998).

For two possibly non-stationary series $\left\{x_{t}\right\}$ and $\left\{y_{t}\right\}$, we construct the cumulative sum $X_{t}=\sum_{i=1}^{t} x_{i}$ and $Y_{t}=\sum_{i=1}^{t} y_{i}$ for $t=1,2, \ldots, \mathrm{N}$, where $\mathrm{N}$ is the same length for both series. ${ }^{4}$ According to $\mathrm{Xu}$ et al. (2005) and Arianos and Carbone (2007), the moving average functions $\tilde{X}_{t}$ and $\tilde{Y}_{t}$ are defined as

$$
\begin{aligned}
& \tilde{X}_{t}=\frac{1}{s} \sum_{k=-\lfloor(s-1) \theta\rfloor}^{\lceil(s-1)(1-\theta)\rceil} X_{t-k}, \\
& \tilde{Y}_{t}=\frac{1}{s} \sum_{k=-\lfloor(s-1) \theta\rfloor}^{\lceil(s-1)(1-\theta)\rceil} Y_{t-k},
\end{aligned}
$$

where the position parameter $(\theta)$ varies from 0 to $1 .^{5}$ The reference point $(\theta)$ of the moving average is set in the sliding window $(s) .\lfloor x\rfloor$ denotes the largest integer less than $(x)$, and $\lceil x\rceil$ consists of the smallest integer greater than $(x)$. The residual series is obtained by subtracting the trend $\tilde{X}(i)$ from $X(i), \varepsilon_{X}(i)=X(i)-\tilde{X}(i)$ and in the same way, we obtain

\footnotetext{
4 In Appendix Fig. 5, we present the dynamics of the cumulative sum of our returns (Fig. 5) to show the trend behavior of these series motivating the detrending moving average method.

5 Different cases exist for setting the parameter $(\theta)$. In this study, we follow Shao et al. (2012), who used the centered moving average $(\theta=0.5)$, as this leads to the best solution. For other cases of setting the parameter $(\theta)$, refer to Ftiti et al., (2019, p. 3125).
} 
$\varepsilon_{Y}(i)=Y(i)-\tilde{Y}(i)$ where $s-\lfloor(s-1) \theta\rfloor \leq i \leq N-\lfloor(s-1) \theta\rfloor$. We divide the residual series into $N_{s}$ parts of equal size $s$, where $N_{s}$ corresponds to the integer part of $\left(\frac{N}{s}-1\right)$. For $1 \leq i \leq s, \varepsilon_{v}(i)=\varepsilon(l+i)$, where $l=(v-1) s$ and each part of the divided residual series is denoted by $v$. We can calculate the root mean square function $f_{v}(s)$ with segment size $s$ by

$$
f_{v}^{2}(s)=\frac{1}{s} \sum_{i=1}^{s}\left[\varepsilon_{v}(i)\right]^{2}
$$

The overall detrended fluctuation functions of each time series are estimated as follows:

$$
\begin{aligned}
& F_{X, D M A}^{2}(s)=\frac{1}{N_{s}} \sum_{v=1}^{N_{s}} f_{X, v}^{2}(s) \\
& F_{Y, D M A}^{2}(s)=\frac{1}{N_{s}} \sum_{v=1}^{N_{s}} f_{Y, v}^{2}(s)
\end{aligned}
$$

and the bivariate fluctuation function $F_{D M C A}^{2}$, following Jiang and Zhou (2011), is defined as

$$
F_{D M C A}^{2}(s)=\frac{1}{N_{s}} \sum_{v=1}^{N_{s}}\left(X_{t}-\tilde{X}_{t}\right)\left(Y_{t}-\tilde{Y}_{t}\right)
$$

The DMCA coefficient ${ }^{6}$ can be easily obtained by following Zebende (2011) for the DCCA coefficient, as follows:

$$
\rho_{D M C A}(s)=\frac{F_{D M C A}^{2}(s)}{F_{X, D M A}(s) F_{Y, D M A}(s)}
$$

According to the Cauchy-Schwarz inequality, we have $-1<\rho_{D M C A}(s)<1$. A value of $\rho_{D M C A}$ equal to zero implies independence between the two-time series. A value equal to $(-1)$ indicates that the two-time series have perfect long-range negative cross-correlation. A value equal to (1) means that the time series have perfect long-range cross-correlation.

Equation (7) shows that the DMCA coefficient is the ratio between the detrended covariance function $F_{D M C A}^{2}$ and the detrended variance function $F_{D M A}^{2}$. This considers only the level of cross-correlation in the mean and makes the measure unsuitable for other amplitudes. In other words, the values of $\rho_{D M C A}$ might not be the same for all fluctuations (lower $q<0$ and higher $q>0$ ).

To surpass this limit, we propose a multifractal generalization of the detrending moving average cross-correlation coefficient. The idea is the same as that of Kwapien et al. (2015), and consists of making the coefficient DMCA to the power $(q)$, so that it becomes more attractive by making it depend on the exponent $(q)$ and the temporal scale $(s)$. Our new measure is based on the so-called $\left(q^{t h}\right)$-order fluctuation function $F_{q}(s)$ from the MFDMA and MF-X-DMA methods (Gu \& Zhou, 2010; Jiang \& Zhou, 2011). Therefore, we use the detrended covariance sign, which enables us to keep "all" information about the analyzed time series (Oświęcimka et al., 2014). These quantities are defined as follows:

$$
\begin{gathered}
F_{X / Y}^{q}(s)=\frac{1}{N_{s}} \sum_{v=1}^{N_{s}} f_{X / Y, v}^{q}(s), \\
F_{X Y}^{q}(s)=\frac{1}{N_{s}} \sum_{v=1}^{N_{s}} \operatorname{sign}\left[f_{X Y}^{2}(s)\right]\left|f_{X Y}^{2}(s)\right|^{\frac{q}{2}},
\end{gathered}
$$

\footnotetext{
6 In this study, the presentation of the DMCA coefficient is different from those of Kristoufek (2014b). Specifically, The DMA method presented in Kristoufek (2014b) is based on scaling of fluctuations with moving average window length whereas in our case, we use moving averages, which are based on box splitting and scaling with box sizes, as described in Eqs. (4) and (5).
} 


$$
\text { where, } f_{X Y}^{2}(s)=\frac{1}{s} \sum_{i=1}^{s} \varepsilon_{X, v}(i) \varepsilon_{Y, v}(i)
$$

Finally, we propose the new detrending moving average $\left(q^{\text {th }}\right)$-order cross-correlation coefficient (q-DMCA cross-correlation coefficient) as follows,

$$
\rho_{q-D M C A}(s)=\frac{F_{X Y}^{q}(s)}{\sqrt{F_{X}^{q}(s) F_{Y}^{q}(s)}}
$$

For $q>0$, according to the Cauchy-Schwarz inequality, we have

$$
-1<\rho_{q-D M C A}<1
$$

When $q<0$, the absolute value of the coefficient q-DMCA is greater than 1 , and this occurs frequently when the bivariate series are not cross-correlated or are weakly crosscorrelated. To consider this case, the q-DMCA coefficient can be redefined as follows:

$$
\rho_{q-D M C A}^{*}(s)=\left\{\begin{array}{c}
\rho_{q-D M C A}(s) \text { if }\left|\rho_{q-D M C A}(s)\right| \leq 1 \\
{\left[\rho_{q-D M C A}(s)\right]^{-1} \text { if }\left|\rho_{q-D M C A}(s)\right|>1}
\end{array}\right.
$$

The cross-correlation coefficient presented in Eq. (11) is a time-scale varying measure generalized for order $q$ but it is time independent. To obtain a time-varying cross-correlation measure generalized for order $q$, we apply the rolling windows based on the q-DMCA coefficient. This method was first proposed by Cajueiro and Tabak (2004), who applied it for efficient performance of the daily WTI and Brent crude oil futures prices. One relevant point to note is that the length of rolling windows can be adjusted to suitable levels for the research needs. The rolling window length is 3162 observations $^{7}$ (approximately 2 months), since using a short length could be associated with poor predictability of the fluctuation function (Zhou et al., 2006).

\section{Numerical experiments for the proposed measure q-DMCA}

Previous studies dealing with either DMCA or DCCA measures as power-law of correlation have confirmed the superiority of these measures compared to the traditional correlation coefficient (Kristoufek, 2014a, 2014b). Actually, Kristoufek (2014a) proposed the DCCA coefficient to measure correlation between non-stationary series, as an alternative to classical measures, such as the Pearson coefficient. Based on Monte Carlo simulation of the ARFIMA model, Kristoufek (2014a) showed the superiority of the DCCA coefficient compared to the Pearson coefficient. Moreover, Kristoufek (2014b) introduced another measure to compute the correlation between non-stationary series, based on the DMCA, as an alternative to the Pearson coefficient. Similarly, through a Monte Carlo simulation exercise based on an ARFIMA model, he showed the superiority of the DMCA coefficient compared to the Pearson coefficient. Overall, these studies concern the power-law correlation for moment of order two, which is analogous to the Pearson correlation measure, and there is consensus on the superiority of the DCCA and DMCA compared to the Pearson correlation coefficient in terms of (i) quantifying scale-dependent correlations and (ii) no sensitivity to noise (Piao \& Fu, 2016).

7 We have also estimated the q-DMCA coefficient with different rolling window lengths (1 and 4 weeks). Since the results remain robust across all window lengths, we have chosen the most parsimonious length. 
In our study, we extend these studies for high moments to measure the correlation between time series in extreme events, particularly for moment of order four, which is not the case for the Pearson correlation. Therefore, to highlight the superiority of our measure and particularly its interest in relation to our research question on the hedging and safe haven capabilities of gold, we should compare our proposed correlation measure with another one dealing with cross-correlation for high moments, such as q-DCCA developed by Kwapień et al. (2015). Therefore, we aim to compare the q-DMCA with the q-DCCA.

Our q-DMCA coefficient is compared to the q-DCCA coefficient by using a numerical experiment based on MC-ARFIMA processes, which allow for various specifications of univariate and bivariate long-term memory (Kristoufek, 2013). The two methods are focused on estimating the generalized power-law coherency parameter $H_{\rho}(q)$ by controlling the generalized univariate Hurst exponents $H_{x}(q), H_{y}(q)$ and the generalized bivariate Hurst exponent $H_{x y}(q)$. Kristoufek (2013) showed that the processes $\left(x_{t}\right)$ and $\left(y_{t}\right)$ are separately and jointly widely stationary (Kristoufek, 2013, pp. 6491-6492). Then, Kristoufek (2017) simulated the MC-ARFIMA model by considering $d_{1}=d_{4}=0.4$ and $d_{2}=d_{3}=0.3$, supporting the wide stationarity of the data. However, Kristoufek (2014a, 2014b) simulated a DMCA coefficient based on the ARFIMA model allowing different cases of $d_{1}=d_{2} \equiv d=0.1,0.4,0.6,0.9,1.1,1.4$ to consider both stationary and non-stationary cases for the variables. We consider the model of MC-ARFIMA, as it has a variety of advantages. It allows us to control for the separate and bivariate Hurst exponents if the bivariate exponent is not higher than the average of the separate ones; in addition, it allows for short-range dependence. Specifically, the proposed MC-ARFIMA model allows for even more specifications that encompass fractional cointegration and a short-range cross-correlated AR process.

The parameter $H_{\rho}$ is defined as $H_{\rho}(q)=H_{x y}(q)-\frac{1}{2}\left(H_{x}(q)+H_{y}(q)\right)$.

The MC-ARFIMA processes are defined as

$$
\begin{aligned}
x_{t} & =\sum_{n=0}^{+\infty} a_{n}\left(d_{1}\right) \varepsilon_{1, t-n}+\sum_{n=0}^{+\infty} a_{n}\left(d_{2}\right) \varepsilon_{2, t-n} \\
y_{t} & =\sum_{n=0}^{+\infty} a_{n}\left(d_{3}\right) \varepsilon_{3, t-n}+\sum_{n=0}^{+\infty} a_{n}\left(d_{4}\right) \varepsilon_{4, t-n}
\end{aligned}
$$

for specific $d_{i}=H_{i}-0.5$, we define $a_{n}\left(d_{i}\right)$ as

$$
a_{n}\left(d_{i}\right)=\frac{\Gamma\left(n+d_{i}\right)}{\Gamma(n+1) \Gamma\left(d_{i}\right)}
$$

and innovations are characterized by

$$
\begin{gathered}
\left\langle\varepsilon_{i, t}\right\rangle=0 \text { for } i=1,2,3,4 \\
\left\langle\varepsilon^{2}{ }_{i, t}\right\rangle=\sigma_{\varepsilon_{i}}^{2} \text { for } i=1,2,3,4 \\
\left\langle\varepsilon_{i, t} \varepsilon_{j, t-n}\right\rangle=\text { ofor } n \neq \text { Oand } \mathrm{i}, \mathrm{j}=1,2,3,4 \\
\left\langle\varepsilon_{i, t} \varepsilon_{j, t}\right\rangle=\sigma_{i j} \text { for } i \neq j \text { and } \mathrm{i}, \mathrm{j}=1,2,3,4
\end{gathered}
$$

We have $H_{x}=d_{1}+0.5, H_{y}=d_{4}+0.5$ and $H_{x y}=0.5+\frac{1}{2}\left(d_{2}+d_{3}\right)$. In the simulations, we initialize the following parameters: $d_{1}=d_{4}=0.4, d_{2}=d_{3}=0.2$. Thus, the theoretical values of Hurst exponents and the power coherency parameter equal $H_{x}=H_{y}=0.9$, $H_{x y}=0.7$ and $H_{\rho}=-0.2$. Following Kristoufek (2017), we set three different simulated 
time-series lengths $\left(T=500,1000\right.$, and5000). Power-law coherency is obtained when $\varepsilon_{2}$ and $\varepsilon_{3}$ are correlated, and thus, we study three correlation levels: $0.1,0.5$, and0.9. For each correlation level, we simulate 1000 bivariate series. ${ }^{8}$ To obtain the estimated values of $H_{\rho}(q)$, we use the variance and covariance scale relations:

$$
\begin{gathered}
F_{x}(q, s) \sim s^{H_{x}(q)} \\
F_{y}(q, s) \sim s^{H_{y}(q)} \\
F_{x y}(q, s) \sim s^{H_{x y}(q)}
\end{gathered}
$$

and then, we obtain the generalized scaling squared correlation as follows:

$$
\rho_{q-D M C A}^{2}(s) \sim \frac{s^{2 q H_{x y}(q)}}{s^{q H_{x}(q)} s^{q H_{y}(q)}}=s^{2 q H_{x y}(q)-q H_{x}(q)-q H_{y}(q)}=s^{2 q H_{\rho}(q)}
$$

The estimated values of $H_{\rho}(q)$ are easily obtained by using log-log regression. Simulation results are performed according to three criteria: bias, variance, and mean squared error (MSE, the sum of squared bias and variance) of the estimators.

We are interested only in the order $q=2$ and $q=4$, as explained in Sect. 3.

The simulation results for $q=2$ of the q-DMCA and q-DCCA methods are presented in Tables 1 and 2, respectively. First, we deduce that the detrended covariance sign in our results significantly improves the results of Kristoufek (2017), especially for the q-DMCA analysis.

Second, for low correlation between error terms $\varepsilon_{2}$ and $\varepsilon_{3}$, the bias is roughly 0.5 and 0.4 for the DCCA- and DMCA-based methods, respectively. The situation improves substantially when the correlation between $\varepsilon_{2}$ and $\varepsilon_{3}$ increases, due to very low variance of the estimators.

The best case occurs when the correlation between innovations equals 0.9 and the window size is the shortest $\mathrm{n}_{\min }=10$ and $\mathrm{s}_{\max }=20$ for the estimators q-DCCA and q-DMCA, respectively. We can generally say that the bias and variance decrease with time-series length. For a sample of 5000 observations, we have approximately 0.03 (bias) and 0.03 (SD) for the DCCA method and 0.02 (bias) and 0.02 (SD) for the DMCA method.

The simple change made to the detrended covariance by introducing the sign is evidence of the main advantage in term of bias and variance. This fact can be explained by the ability of the estimators to capture almost all information.

We conclude from Tables 1 and 2 that for both methods, when the correlation between error terms $\varepsilon_{2}$ and $\varepsilon_{3}$ increases, the results improve significantly.

Similarly, the simulation results for $q=4$ of the q-DMCA and q-DCCA coefficients are presented in Tables 3 and 4, respectively. First, we note that the two methods yield a good estimation of parameter $H_{\rho}$ when we focus on the analyses of high fluctuations. Second, the findings are independent of the level of correlation and the sample length. In other words, when we change the setting, the results remain relevant. Similarly, the best situation for high fluctuations is when the correlation between $\varepsilon_{2}$ and $\varepsilon_{3}$ is lower $(\rho=0,1)$.

To improve our numerical study, we extend the length of samples to 100,000 observations (we set window sizes $\mathrm{n}_{\min }=10$ and $\mathrm{s}_{\max }=20$, which are the best cases in the previous simulations with correlation between innovations equal to 0.9 and 0.1 for $q=2$ and $q=4$, respectively). The purpose of doing so is to verify whether the methods are stable with respect to the length of the sample and for further comparison between them (to check whether the alignment between the two methods remains valid).

8 We follow the setting of Kristoufek (2017) to assess the introduction of the sign function in the detrended covariance function. 


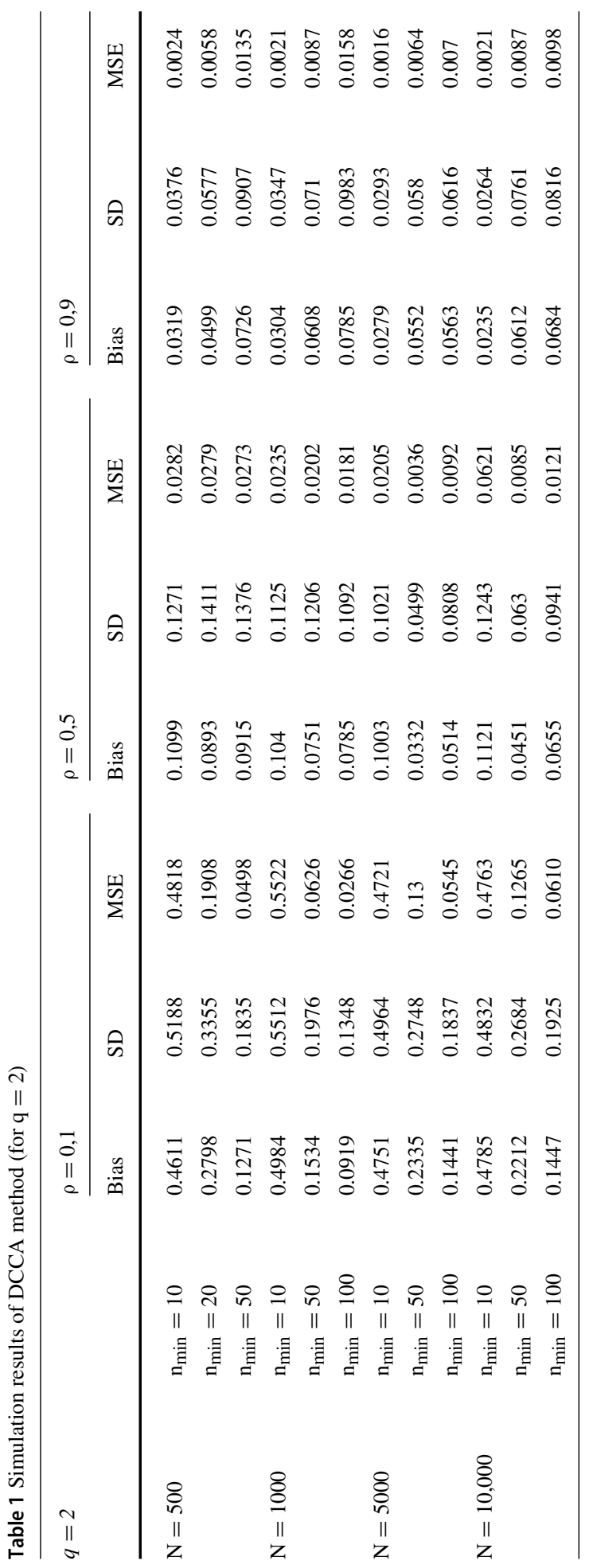




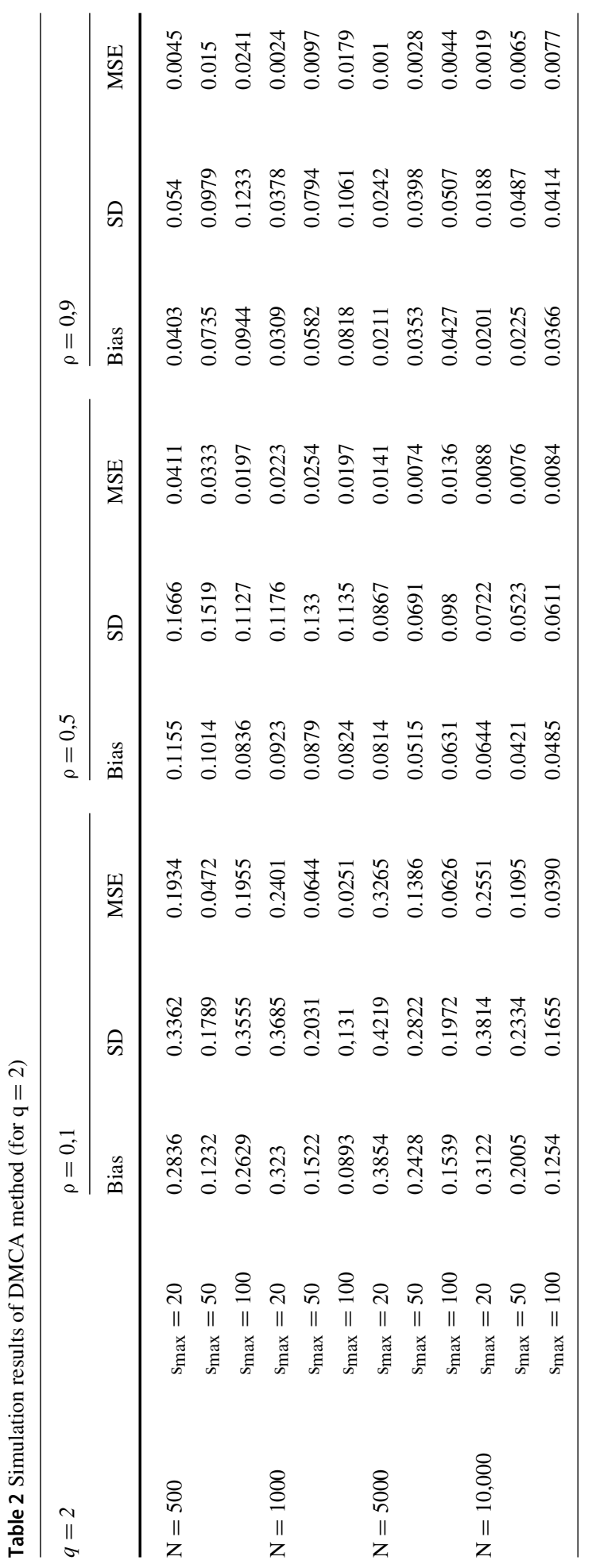




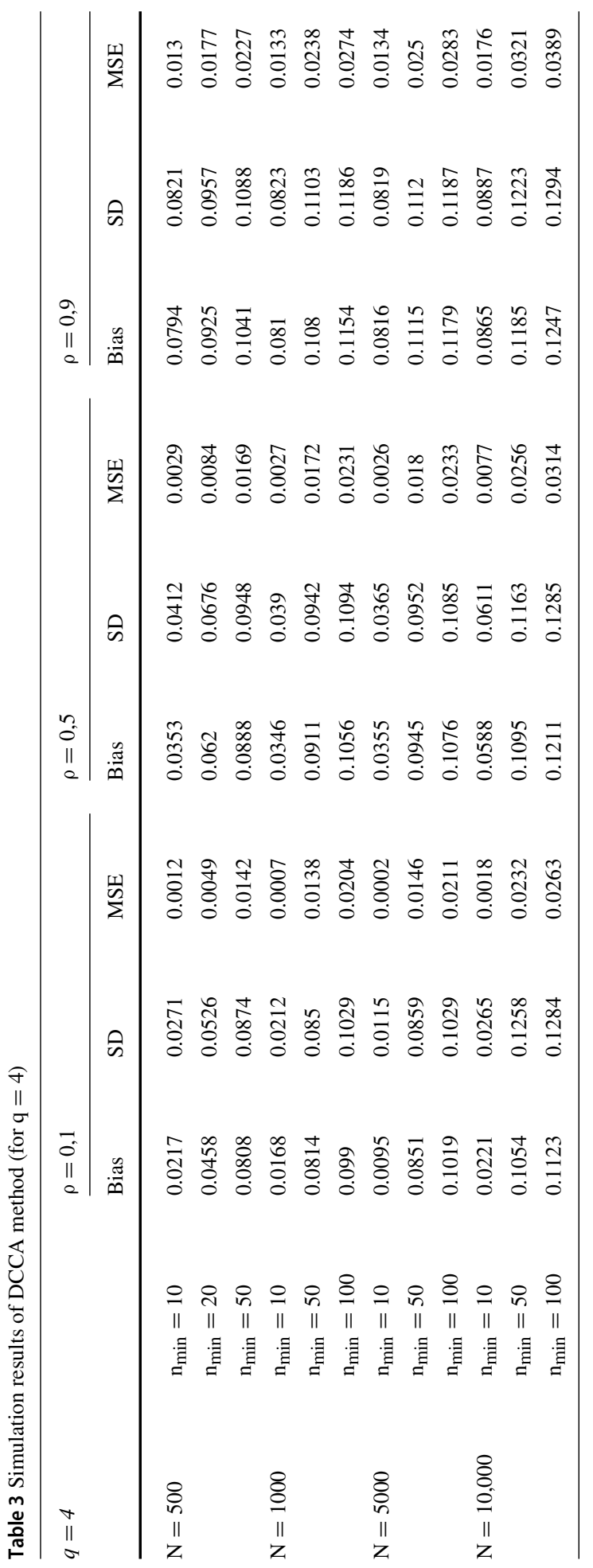




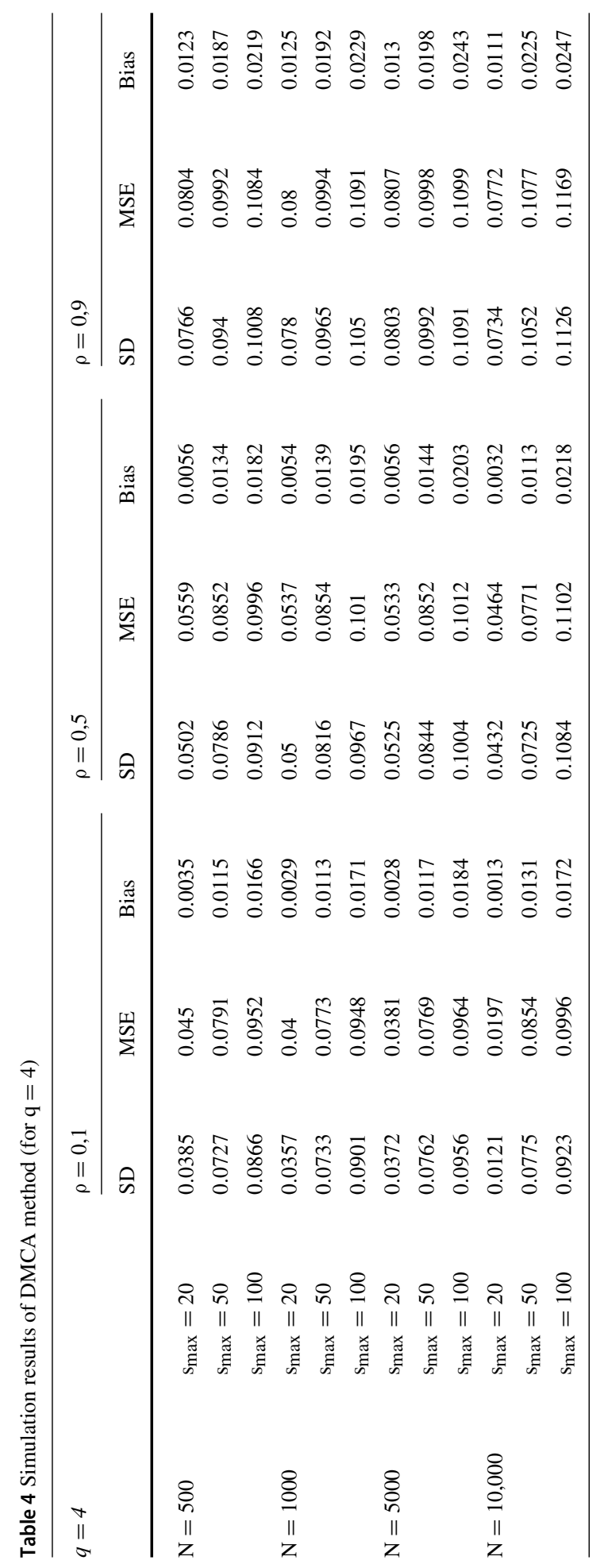




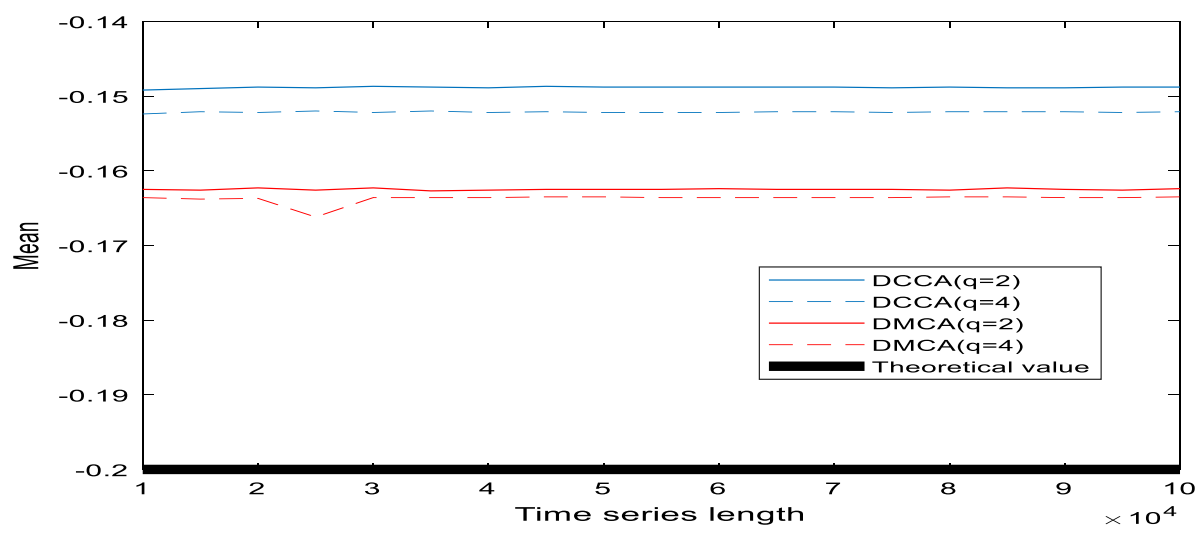

Fig. 1 Comparative analyses of DCCA and DMCA methods

Figure 1 shows the estimation values of the parameter $H_{\rho}$ against time-series length. The main deduction from the results is that the two methods show a stable estimation (in mean) regardless of the length of the sample. For $q=2$, the estimation values are approximately equal to -0.15 and -0.16 for the q-DCCA and q-DMCA methods, respectively. There is almost the same result for $q=4$, as shown by the dashed lines in Fig. 1. Based on a comparison with the theoretical value, which equals -0.2 , we deduce that the q-DMCA method is more efficient than the q-DCCA method.

\section{Empirical validation}

\subsection{Data and preliminary analysis}

This study employs high frequency data (5-min intervals), which enables us to investigate important and interesting information and capture further phenomena at short-term intervals. The data related to the gold futures (expressed in USD per ounce), the light sweet crude oil (expressed in USD per barrel) futures contracts. For exchange rates, we select the currencies of the main trade partners of the United States: Euro (EUR), pound sterling (GBP), Swiss franc (CHF), Japanese yen (JPY), Canadian dollar (CAD), and Australian dollar (AUD). Specifically, we refer to the main currencies forming the US dollar index (DXY). This index aims to measure the value of the USD relative to a basket of foreign currencies, considered as a basket of US trade partners' currencies. This is an aggerate index in 1973 after the dissolution of the Bretton Woods agreement, and has a value of 100. The DXY index is quoted in high-frequency data and provides information about the global trend of the USD. Previous literature (e.g., Barnett et al., 2013) highlights that analyzing aggregated data may be source of bias. Therefore, we choose to investigate the gold-currency relationship based on the individual exchange currency market forming the DXY aggregate index.

Formally, the DXY index is calculated as the weighted geometric mean of the dollar's value relative to the following selected currencies: (EUR), (JPY), (GBP), (CAD), (SEK), and $(\mathrm{CHF})$, weighted at $57.6 \%, 13.6 \%, 11.9 \%, 9.1 \%, 4.2 \%$, and $3.6 \%$, respectively. Interestingly, for data availability, we replace the SEK with the AUD and this choice is motivated by several reasons. First, since July 4, 1918, Australia and the US have maintained a unique bilateral 
partnership. Central to the relationship are the ANZUS Alliance and the Australia-US Free Trade Agreement. During the period of study 2017-2019, Australia and the US traded more than USD 66 billion yearly in a two-way investment relationship valued at more than USD 1.1 trillion, leading to approximately $25 \%$ of Australia's inward foreign investment being derived from the US. The selected exchange rates are measured in units of foreign currency per USD, where an exchange rate decrease denotes USD depreciation. All data are collected from Bloomberg database on an intraday basis and cover a period of approximately 400 trading days beginning on May 23, 2017 and ending on March 12, 2019. Thus, the sample includes 35,608 observations for each variable. This period choice is motivated by our discretion to analyze the role of the gold outside of the COVID-19 period, as it is considered a specific shock similar to nature disaster (Goodell, 2020). The return series of gold, oil, and currency are computed on a continuous compounding basis as the first difference of log prices. Figure 2 presents the dynamic of the gold-oil price (Fig. 2a) and gold price-exchange rate dynamics for the different currencies analyzed in our study (Fig. 2b-g).

Figure 2 shows the following noteworthy aspects. First, we observe a potential negative co-movement between oil and gold prices (Fig. 2a) in a few periods, explained by gold investors holding under an upward trend of oil prices and vice versa. Figure $2 b-g$ present the dynamic of gold with different USD exchange rates. The pattern shows a potential negative relationship between gold and currency markets.

Table 5 presents the main descriptive statistics. Skewness and kurtosis values show asymmetry and leptokurtic dynamics of the studied series, respectively. This behavior is confirmed by the Jarque-Bera test, which rejects the normality of all series. Figure 2 shows volatility clustering for all data, highlighting the high volatility, extreme movements, and large fluctuations of gold, oil, and exchange rates. ${ }^{9}$ Those features motivate the use of a non-linear framework in this study.

Before investigating the dependence between time series through proposing a new multifractal correlation measure for different amplitudes, it is worthwhile to investigate the multifractality nature of the studied series. To do this, we employ the MFDMA and MF-XDMA methods to investigate the degree of multifractality for the univariate and the bivariate series, respectively. For different values of time scale $(s)$, the power relationship between $F_{q}(s)$ and $(s)$ is $F_{q}(s) \sim s^{H(q)}$. Furthermore, according to the standard multifractal framework, the multifractal scaling exponent, $\tau(q)=q H(q)-1$ can be used to characterize the multifractal nature. The multifractal series may be characterized based on the singularity strength function, $\alpha(q)=\frac{d \tau(q)}{d q}$. This quantity informs the singularities in a time series and the multifractal spectrum, $f(\alpha)=q[\alpha-H(q)]+1$, obtained through the Legendre transform (Halsey et al., 1986). The strength of multifractality can be estimated by the width of the generalized Hurst exponents $\Delta H=H_{\max }-H_{\min }$ and the multifractal spectrum $\Delta \alpha=\alpha_{\max }-\alpha_{\min }$ for univariate and bivariate series (see Table 6).

To investigate the sources of the multifractality, we employ the shuffling and surrogate procedures ${ }^{10}$ to the original data for 100 times and we re-estimate the degree of multifractality $\Delta H$ and $\Delta \alpha$. Finally, we can decide about the source of multifractality as follows.

- If $\Delta H$ and $\Delta \alpha$ of the original data $>\Delta H$ and $\Delta \alpha$ of the surrogated data $>\Delta H$ and $\Delta \alpha$ of the shuffled data, then the multifractality is caused by the long-range correlation.

\footnotetext{
9 The augmented Dickey-Fuller and Phillips-Perron tests accept the null hypothesis of unit root for all variables and the Kwiatkowski-Phillips-Schmidt-Shin test rejects the null hypothesis of stationarity of all variables.

10 For more details about these procedures, readers can refer to Ftiti et al. (2019).
} 
(a)

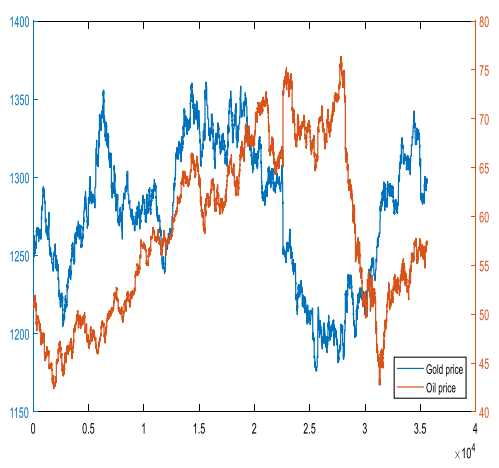

(b)

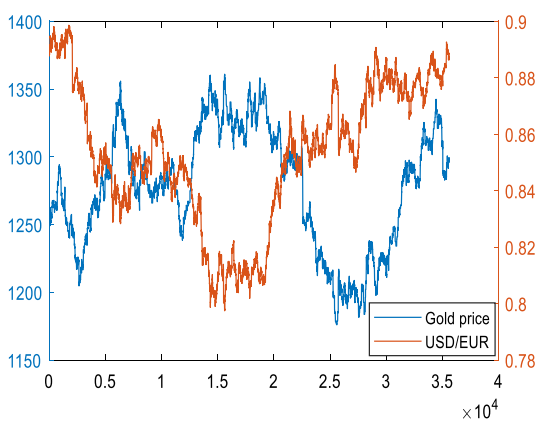

(d)

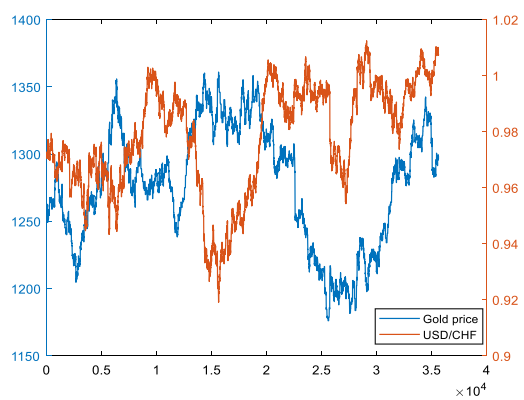

(f)

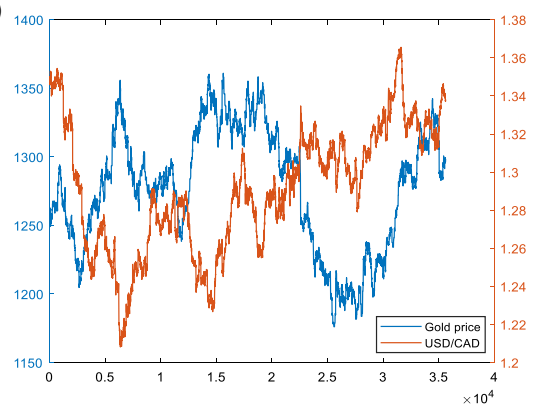

(c)

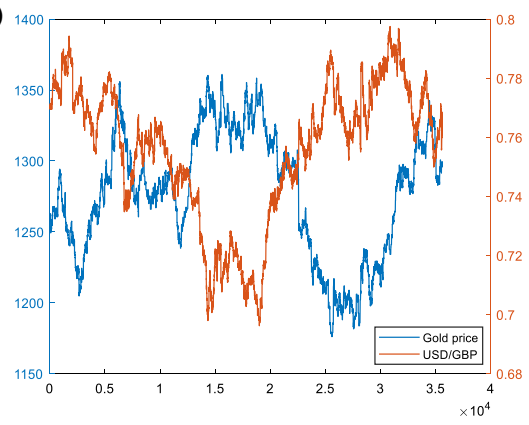

(e)

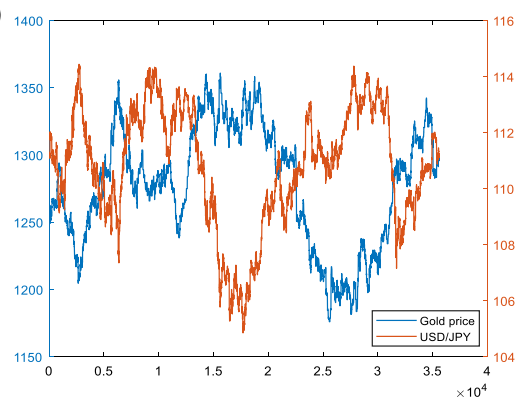

(g)

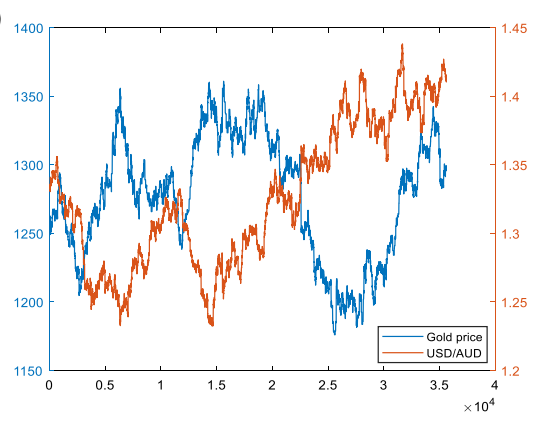

Fig. 2 The dynamic of gold, oil prices and exchange rates 


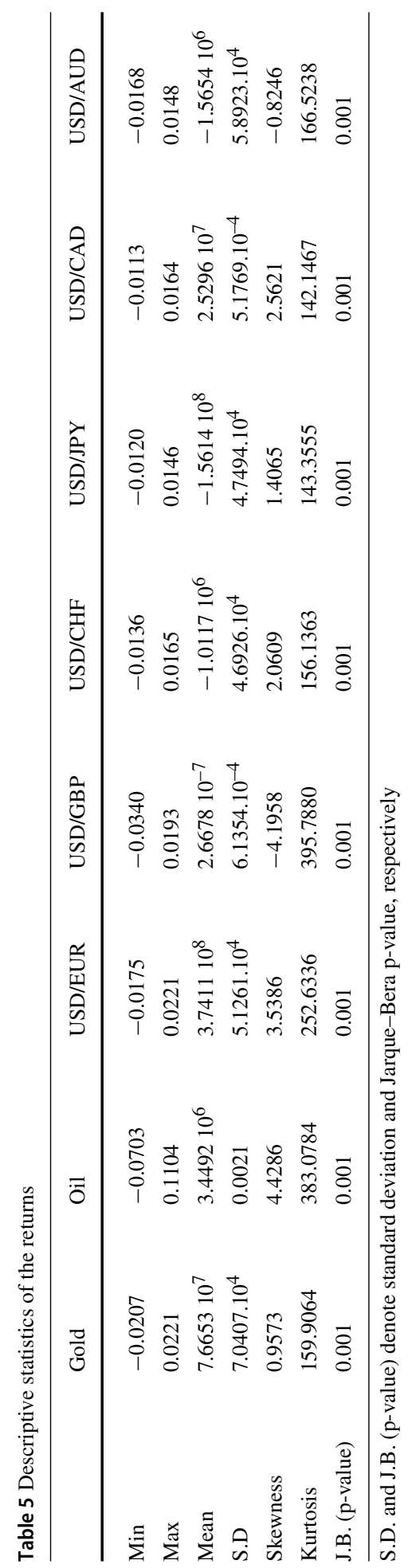


Table 6 Multifractal degrees of univariate and bivariate series

\begin{tabular}{|c|c|c|c|c|c|c|}
\hline \multirow[t]{2}{*}{ Variable } & \multicolumn{3}{|l|}{$\Delta \mathrm{H}$} & \multicolumn{3}{|l|}{$\Delta \alpha$} \\
\hline & $\begin{array}{l}\text { Original } \\
\text { data }\end{array}$ & $\begin{array}{l}\text { Shuffled } \\
\text { data }\end{array}$ & $\begin{array}{l}\text { Surrogate } \\
\text { data }\end{array}$ & $\begin{array}{l}\text { Original } \\
\text { data }\end{array}$ & $\begin{array}{l}\text { Shuffled } \\
\text { data }\end{array}$ & $\begin{array}{l}\text { Surrogate } \\
\text { data }\end{array}$ \\
\hline Gold & 0.4094 & 0.2966 & 0.3860 & 0.6025 & 0.4465 & 0.4816 \\
\hline Oil & 0.4513 & 0.4387 & 0.4224 & 0.6176 & 0.6057 & 0.5822 \\
\hline Bivariate & 0.3680 & 0.1924 & 0.2325 & 0.5352 & 0.2962 & 0.3632 \\
\hline USD/EUR & 0.4707 & 0.3591 & 0.3585 & 0.6553 & 0.5171 & 0.5064 \\
\hline Bivariate & 0.3405 & 0.1701 & 0.2259 & 0.5200 & 0.2899 & 0.4912 \\
\hline USD/GBP & 0.5227 & 0.3892 & 0.3967 & 0.7366 & 0.5498 & 0.5557 \\
\hline Bivariate & 0.3773 & 0.1621 & 0.2152 & 0.5562 & 0.2534 & 0.4648 \\
\hline USD/CHF & 0.3838 & 0.3226 & 0.3319 & 0.5462 & 0.4640 & 0.4728 \\
\hline Bivariate & 0.3914 & 0.1837 & 0.1726 & 0.5687 & 0.2712 & 0.2577 \\
\hline USD/JPY & 0.4699 & 0.3188 & 0.3470 & 0.6501 & 0.4710 & 0.4821 \\
\hline Bivariate & 0.2790 & 0.2232 & 0.1756 & 0.3936 & 0.3277 & 0.2725 \\
\hline USD/CAD & 0.4091 & 0.3121 & 0.3014 & 0.5666 & 0.4341 & 0.4255 \\
\hline Bivariate & 0.3590 & 0.2043 & 0.1937 & 0.5365 & 0.3358 & 0.3294 \\
\hline USD/AUD & 0.4024 & 0.3195 & 0.3275 & 0.5551 & 0.4379 & 0.4494 \\
\hline Bivariate & 0.3724 & 0.1875 & 0.1893 & 0.5599 & 0.2981 & 0.3002 \\
\hline
\end{tabular}

Bivariate series refers to the relationship between gold and the other variables under study. $\Delta H$ and $\Delta \alpha$ represent the degree of multifractality measures from the generalized Hurst exponents and the multifractal spectrum, respectively

- If $\Delta H$ and $\Delta \alpha$ of the original data $>\Delta H$ and $\Delta \alpha$ of the shuffled data $>\Delta H$ and $\Delta \alpha$ of the surrogated data, then the multifractality is caused by the fat-tailed distribution.

When the degree of multifractality decreases after the two procedures, we conclude that both the long-range correlation and fat-tailed distribution contribute to the multifractality.

It is widely known that the multifractal spectrum (generalized Hurst exponent) of a monofractal time series is a point (order q independent), that is, the widths of the multifractal spectrum and the generalized Hurst exponent are zero, whereas, they are different than zero for multifractal time series. Table 6 shows that the widths for all studied series in the univariate case are significantly non-zero, which supports the multifractal behavior of our studied series. From a separate markets point of view, we can deduce that long memory and fat-tailed distribution significantly contribute to the multifractality, since the degree of multifractality decreases after both shuffle and surrogate procedures. Moreover, for the bivariate cases (all series with gold markets), the results show that the widths are also significantly non-zero, confirming the multifractality in the bivariate cases. From an integrated markets point of view, we have different conclusions. First, the degree of multifractality decreases after the shuffle procedure for gold-oil, gold-EUR, and gold-GBP relationships, which indicates that long memory plays a crucial role in the sources of multifractality. Second, there is evidence that both long memory and fat-tailed distribution contribute to the multifractality for the gold-CHF, gold-CAD, and gold-AUD relationships. Third, the multifractality of the gold-JPY relationship is explained only by the fat-tailed distribution. 
Based on the abovementioned results, there is evidence of non-linear dependency and multifractality for the gold-oil and gold-USD relationships, which indicates the vulnerability to the use of a normal and linear framework.

\subsection{Is gold a hedge or a safe haven against oil and the USD?}

\subsubsection{Evidence from time-scale varying measure}

We apply an extension of the detrending moving average cross-correlation analysis to gold, oil, and exchange rate return series using the q-DMCA cross-correlation coefficient for different window lengths from 20 observations ( $1.5 \mathrm{~h}$ ) to 3162 observations (approximately 2 months). For each pair of composite variables, we estimate the coefficient $\rho_{q-D M C A}(s)$ for the medium $(q=2)$ and high fluctuations $(q=4)$.

The correlations between gold, oil, and exchange rates computed from Eq. (11) are shown in Fig. 3a. Overall, we note that the cross-correlations between bivariate series are not the same for different window sizes which yields useful policy implications, as we consider a large set of agents with different investment horizons, such as market participants, traders, hedges funds, and policymakers.

Regarding the relationship between gold and oil, empirical results indicate independence between the two markets for medium fluctuations $(q=2)$, regardless of the time scale which shows a correlation close to zero for all time scales. This result makes it possible for gold to act as a weak hedge against oil price movement. For extreme movement, the results (Fig. 3a) show a pronounced relationship in a short time scale (less than 600), with an average correlation of $-15 \%$, and then becomes close to zero. This finding suggests that gold has a capability of acting as a safe haven against extreme oil price movements, particularly for short time scales.

Concerning the dynamic of the relationship between gold and exchange rates, the pattern is different from that with oil. We observe (Fig. 3b-g) that for both medium and large fluctuations, the relationship between gold and currency markets is negative, with more pronounced negative correlation in medium fluctuations $(q=2)$. For large fluctuations, the correlation between gold and currency markets is around $-20 \%$ on average. This result indicates the capability of gold to act as a hedge and safe haven against currency market movements.

To obtain reliable results, we employ a bootstrap test based on the iterative amplitude adjusted Fourier transform, as developed by Schreiber and Schmitz (1996), to control potential correlation between studied series. This method for surrogate data aims to test the non-linearity of the investigated series. The implementation of the test is easy; the statistic is defined as the q-DMCA coefficient; the distribution of the statistic is generated by an ensemble of the statistic $\rho_{q-D M C A}(s)$, which is obtained by applying the surrogated procedure 1000 times; and the q-DMCA coefficient $\rho_{q-D M C A}^{s u r}(s)$ of each couple of surrogated series is calculated. The null hypothesis is that the cross-correlation between original series possesses the same dependence traits as those obtained from surrogated

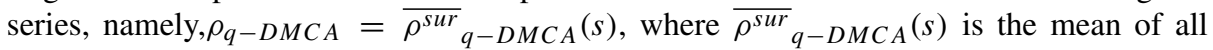
$\rho^{s u r}{ }_{q-D M C A}(s)$ values. The difference in terms of correlation between the original series and the surrogated series is quantitatively described by a two-tailed p-value, which is defined 


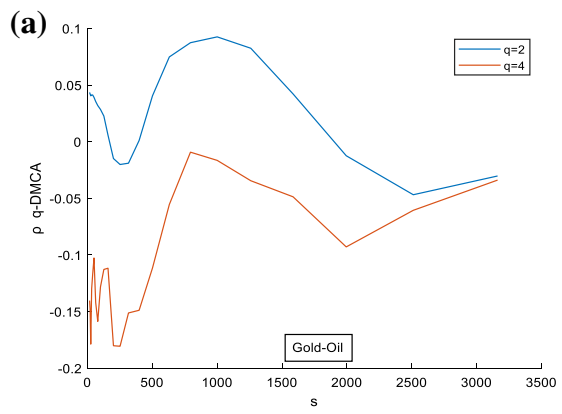

(c)
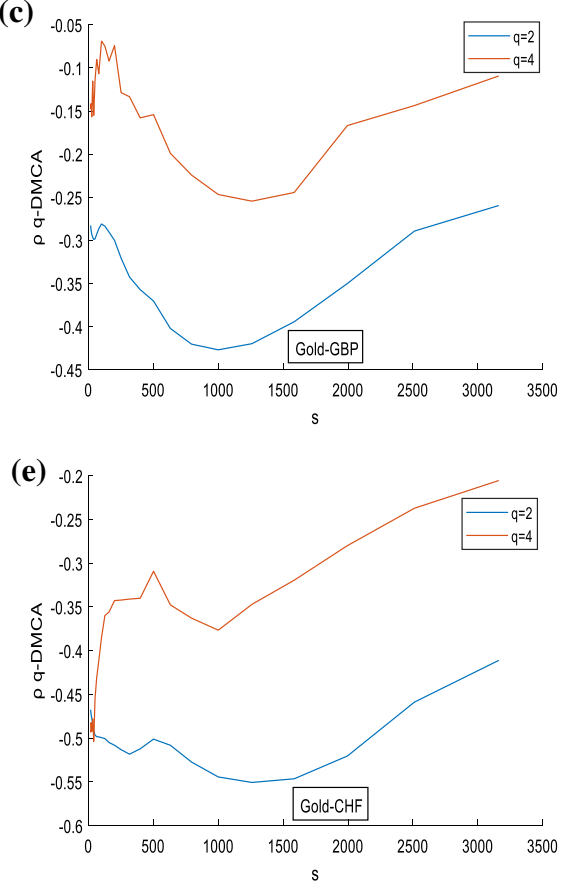

(b)

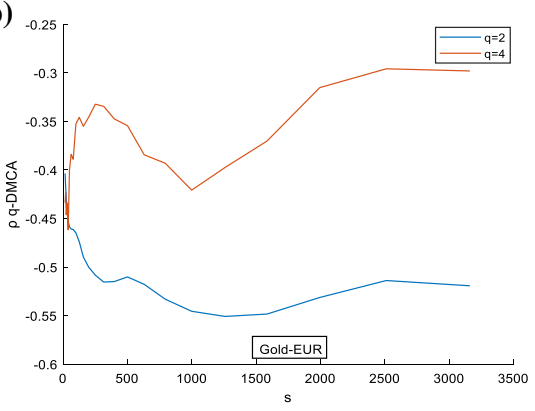

(d)

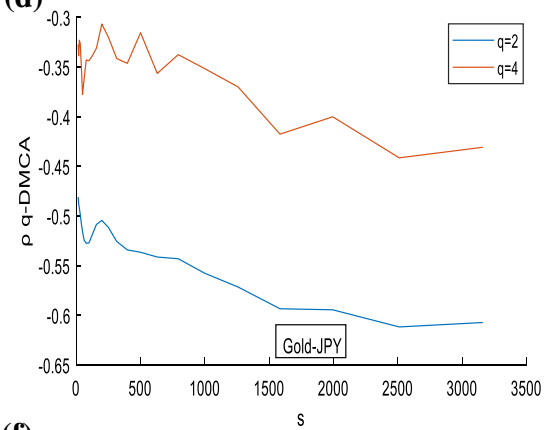

(f)

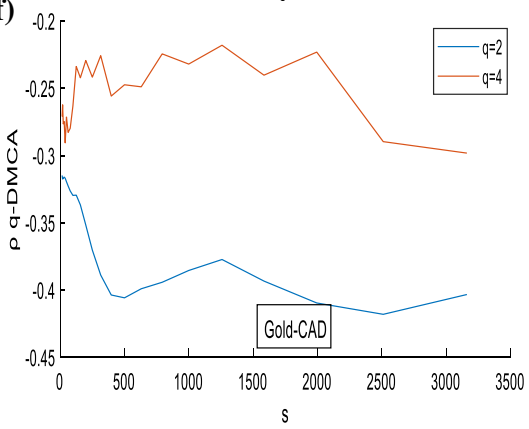

(g)

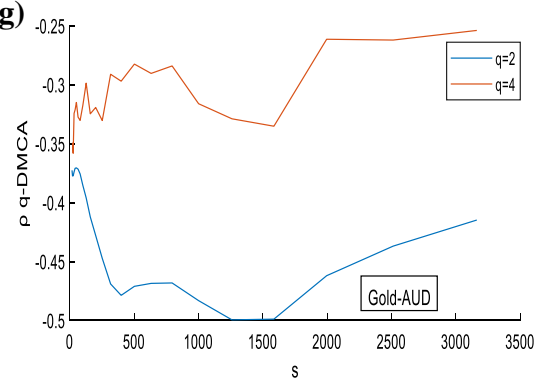

Fig. 3 Cross-correlation at different time scales. a Time scales varying cross-correlation between gold and oil. b Time scales varying cross-correlation between gold and USD/EUR exchange rate. c Time scales varying cross-correlation between gold and USD/GBP exchange rate. $\mathbf{d}$ Time scales varying cross-correlation between gold and USD/JPY exchange rate. e Time scales varying cross-correlation between gold and USD/CHF exchange rate. $\mathbf{f}$ Time scales varying cross-correlation between gold and USD/CAD exchange rate. $g$ Time scales varying cross-correlation between gold and USD/AUD exchange rate 
as

$$
p=\operatorname{Prob}\left(\left|\rho_{q-D M C A}^{\text {sur }}(s)-{\overline{\rho^{s u r}}}_{q-D M C A}(s)\right|>\left|\rho_{q-D M C A}(s)-{\overline{\rho^{s u r}}}_{q-D M C A}(s)\right|\right)
$$

If the null hypothesis cannot be rejected, this implies that gold is a weak hedge (safe-haven) financial instrument.

The results of the bootstrap test are presented in Tables 7 and 8 for the medium and high fluctuations, respectively. Conversely we deduce that gold can act as a significant hedge and safe haven against USD depreciation with differences at different time scales, (Table 7). For the gold-oil relationship, we cannot reject the null hypothesis for average dependence, which leads us to conclude that the two markets are independent in calm periods, (Table 7). Contrarily, there is negative and significant tail dependence between gold and oil for short time scales (Table 8). Our results reveal that gold can hedge against oil price movements weakly but can act as an effective short-term safe haven against extreme oil price movements. Regarding the currency markets, we put out evidence the gold's capability to act as a strong hedge as well as a safe haven against currency market movements (Table 8). This result has implications for currency investors operating at different time horizons, who want to hedge their exposure to currency swings and with downside risks for those horizons.

\subsubsection{Evidence from time-varying cross-correlation measure}

In addition to the developed measure "time scale" described in the previous subsection, we propose a time-varying of our correlation measure generalized for the $q$ th-order based on the rolling windows method. Taking this into consideration provided an empirical basis for building non-linear models rather than the traditional models with a constant coefficient (as discussed in the introduction), which are not suitable for capturing the nature and dynamics of the relationship that exist between gold and oil markets and between the gold market and USD exchange rates.

The time-varying dependence results ${ }^{11}$ are presented in Fig. 4. First, we observe a large variation in the correlation of all pairs of series over time. Concerning the time-varying gold-oil correlation, Fig. 4a shows independence behavior for medium fluctuations $(q=2)$, except for July-August 2018. These results confirm the previous results of gold's hedging ability against oil price movements. For large fluctuations or -extreme movement $(q=4)$, the correlation between oil and gold is sometimes close to zero (July 2017 to February 2018; May 2018 to July 2018; and November 2018 to January 2019) and sometimes negative (February 2018 to July 2018 and October 2018). These results show the safe-haven capability of gold against oil during extreme price movements in these periods.

Regarding the interdependence between gold and currencies markets, we confirm our previous findings of the time-scale varying measure, as we cannot reject the hedging and safe-haven behavior of gold against currency market movements. Figure $4 \mathrm{~b}-\mathrm{g}$ reveal many interesting findings regarding the gold-currency correlations during calm and turmoil periods. First, the time-varying dependence is not constant and differs among currencies. Second, for all currencies, there are many periods with more marked negative values during calm periods than during turmoil periods. Third, the cross-correlations for high fluctuations are very volatile, which explains an investor's risk in composing his or her portfolio in a turmoil

11 To optimize the clarity of the figures, we do not insert the time varying cross-correlations obtained from the 1000 surrogated data series (the outputs are in line with the test results of the previous subsection). However, these are available upon request from the corresponding author. 


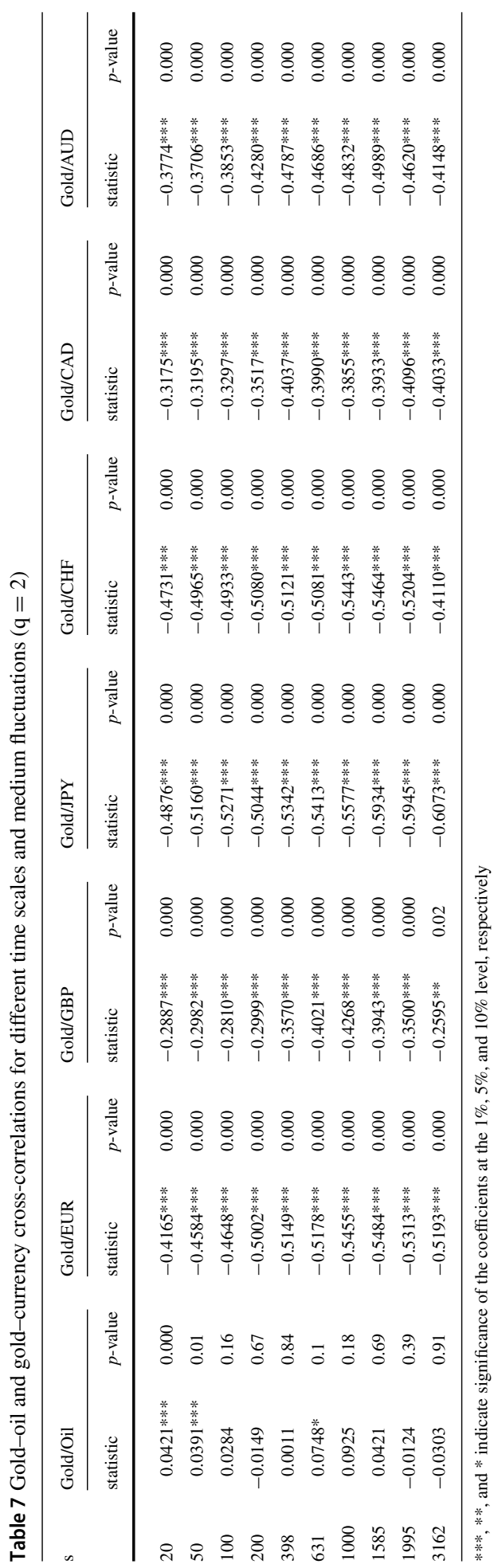




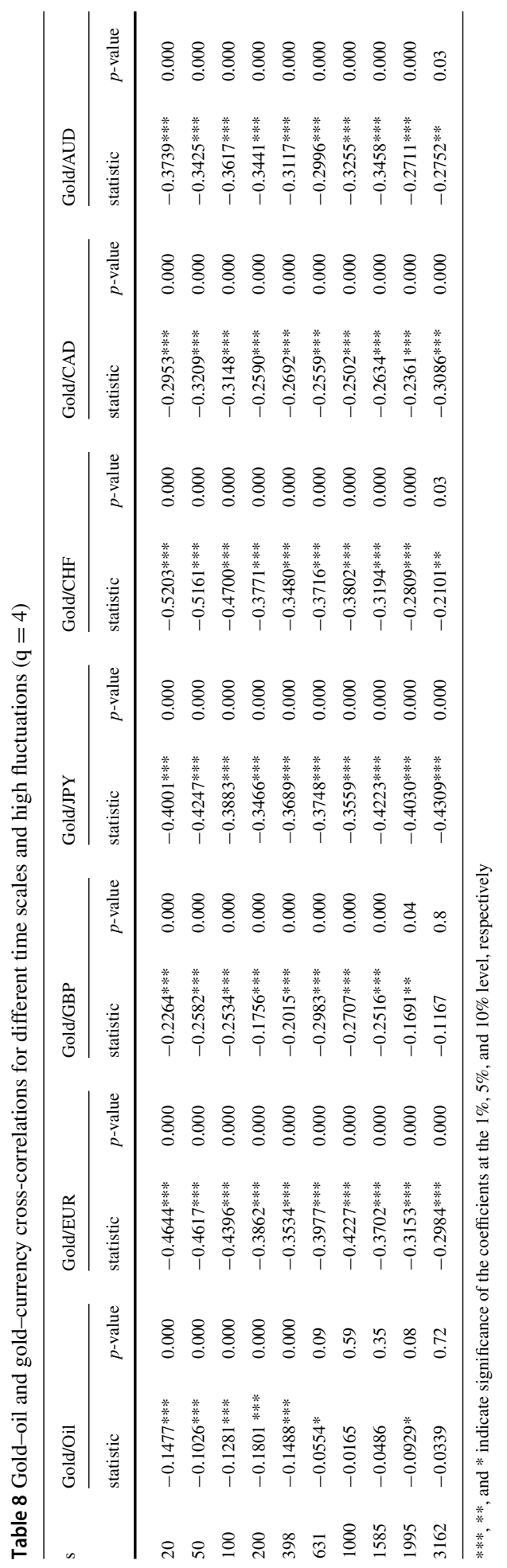



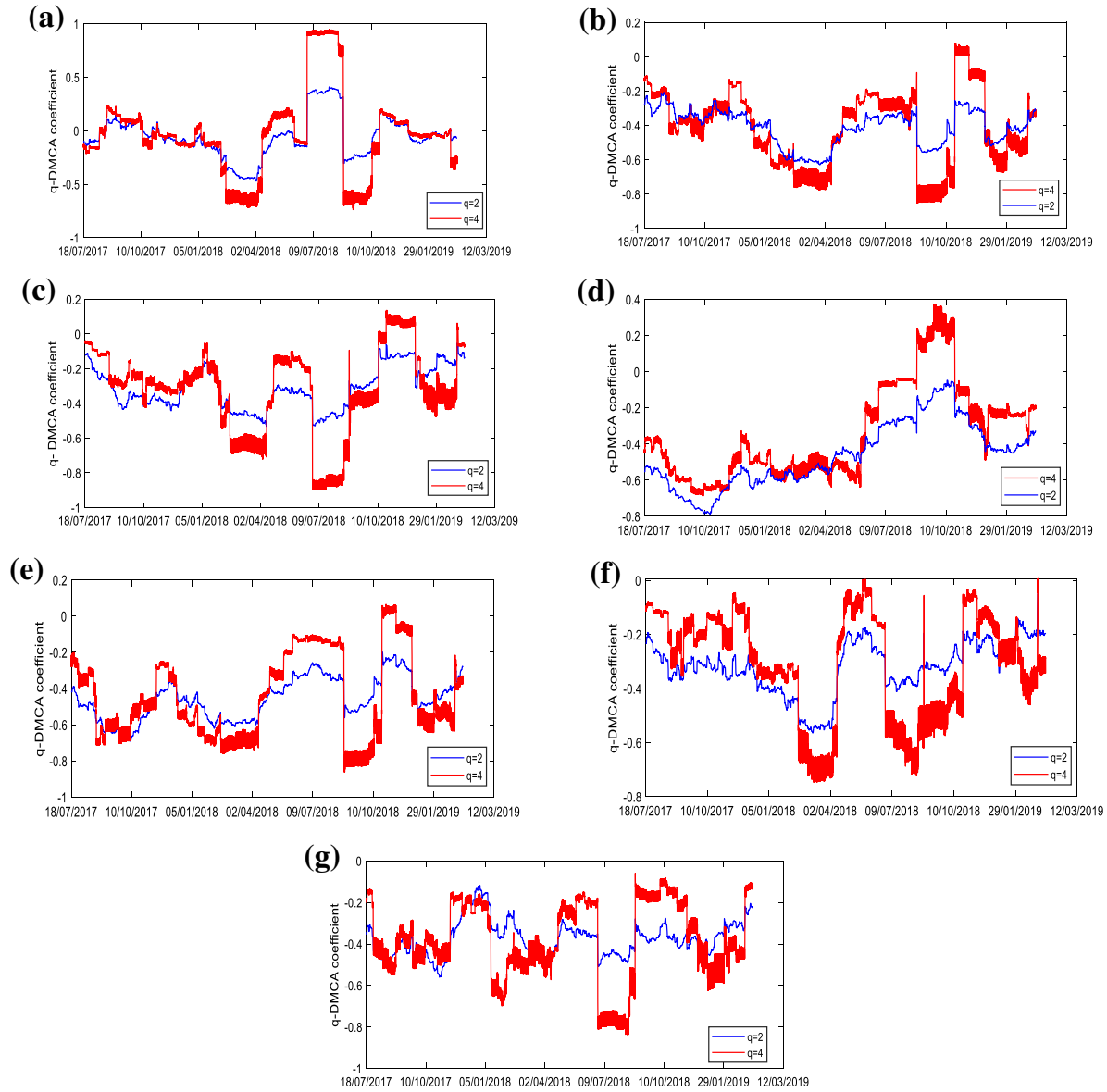

Fig. 4 Time-varying cross-correlation. a Gold and Oil. b Gold and USD/EUR exchange rate. c Gold and USD/GBP exchange rate. $\mathbf{d}$ Gold and USD/JPY exchange rate. e Gold and USD/CHF exchange rate. f Gold and USD/CAD exchange rate. g Gold and USD/AUD exchange rate

period. Overall, the dynamics of the cross-correlation between gold and currency markets shows that gold can act as a hedge and safe haven against currency market movements.

\subsection{Intraday portfolio diversification and hedging ratios}

The study aims to determine the role of gold as a hedge and safe haven for the majority of market participants, including traders, hedge funds, and policymakers. In this context, we evaluate the attractiveness of gold in terms of risk management by taking into consideration normal $(\mathrm{q}=2)$ and turmoil $(\mathrm{q}=4)$ movements derived from currency and oil prices at different time scales $(s)$. Following Kroner and $\mathrm{Ng}$ (1998), the optimal weight of gold in a 1 USD portfolio of gold/(currencies or oil) is given by

$$
w_{g}(s)=\frac{F_{c / o}^{q}(s)-F_{g, c / o}^{q}(s)}{F_{g}^{q}(s)-2 F_{g, c / o}^{q}(s)+F_{c / o}^{q}(s)}
$$




$$
w_{g}(s)=\left\{\begin{array}{cll}
0 & \text { if } & w_{g}(s)<0 \\
w_{g}(s) & \text { if } & 0 \leq w_{g}(s) \leq 1 \\
1 & \text { if } & w_{g}(s)>1
\end{array}\right.
$$

where $g, o$, and $c$ denote gold, oil, and currency, respectively. $F_{c / o}^{q}(s), F_{g}^{q}(s)$, and $F_{g, c / o}^{q}(s)$ refer to the $q^{t h}$-order detrended fluctuation function of the currency, oil, and gold and the $q^{t h}$-order detrended cross-correlation function between different variables and gold for each time scale, respectively. All these series are estimated by using the q-DMCA coefficient. We note that the weight of the currencies (or oil) in the 1 USD gold/(currencies or oil) portfolio for different time scales is $\left(1-\mathrm{w}_{g}\right)$. In addition to the optimal portfolio allocation, investors and market participants seek to minimize the cost risk and the risk of the hedged portfolio. The hedging strategy consists of holding a long spot position in one unit of currency or oil futures market hedged by a short position of $\beta(s)$ in the gold futures market (see, e.g., Kroner \& Sultan, 1993; Hull, 2011), given by

$$
\beta(s)=\frac{F_{g, c / o}^{q}(s)}{F_{g}^{q}(s)}
$$

Tables 9 and 10 display portfolio weights and hedge ratios for calm and turmoil periods, respectively. Beginning with the portfolio weights, in a 100 USD portfolio of gold and oil futures, the optimal portfolio weight of gold futures for calm period varies from 0.8812 USD $(s=398)$ to 0.9136 USD ( $s=1000)$. We deduce that the weight of gold futures in gold and oil futures portfolio remained important and stable as the time scale increased. For gold futures and currency portfolios, weights vary substantially across exchange rates. They range between $12.97 \%(\mathrm{~s}=3162)$ and $24.64 \%(\mathrm{~s}=20)$ for the Euro currency market; $30.17 \%(\mathrm{~s}=$ $1000)$ and $41.59 \%(\mathrm{~s}=100)$ for the Pound currency market; 6.9\% ( $\mathrm{s}=1995)$ and $15.62 \%(\mathrm{~s}$ $=20)$ for the Yen currency market; $8.61 \%(\mathrm{~s}=1585)$ and $22.09 \%(\mathrm{~s}=3162)$ for the Swiss Franc currency market; $24.43 \%(\mathrm{~s}=631)$ and $30.27 \%(\mathrm{~s}=100)$ for the Canadian dollar currency market; and 26.98\% ( $\mathrm{s}=398$ ) and 40.39\% ( $\mathrm{s}=1995)$ for the Australian dollar currency market. These results suggest that i) the weight of gold futures is important in a gold-exchange rate portfolio, especially for a short horizon and ii) the weight of gold futures decreased as the time scale increased for the EUR, JPY, and CHF.

The hedge ratio regarding oil futures fall in the range of $-0.0395(\mathrm{~s}=1995)$ and 0.2626 $(\mathrm{s}=1000)$. This result suggests that to minimize risk for short hedgers in a 4-week trade, a long position of 1 USD in the oil market should be hedged by a short position of 0.0395 USD in the gold market. However, the hedge ratios for currencies are important; they vary from $-0.3036(\mathrm{~s}=20)$ to $-0.3925(\mathrm{~s}=1000)$ for the Euro currency market; $-0.2251(\mathrm{~s}=3162)$ to $-0.3371(\mathrm{~s}=1000)$ for the Pound currency market; $-0.3280(\mathrm{~s}=20)$ to $-0.4090(\mathrm{~s}=3162)$ for the Yen currency market; $-0.2876(\mathrm{~s}=3162)$ to $-0.3544(\mathrm{~s}=1000)$ for the Swiss Franc currency market; $-0.2372(\mathrm{~s}=20)$ to $-0.3157(\mathrm{~s}=1995)$ for the Canadian dollar currency market; and $-0.3088(\mathrm{~s}=50)$ to $-0.4417(\mathrm{~s}=1585)$ for the Australian dollar currency market. We deduce that i) the hedge ratio increased when the time scale increased and ii) investors require more gold assets for intraday investments $(s=20)$ to minimize portfolio risk.

Similarly, the optimal portfolio weight and hedge ratio for turmoil periods are presented in Table 10. The empirical results suggest that the weight of gold futures is also important in gold/oil and gold/currency portfolios, except for the JPY. From the results of the hedge ratio, we find that, contrary to calm periods, in turmoil periods, the hedge ratio decreased when the time scale increased for the oil, EUR, GBP, and CAD. This finding implies that to minimize 


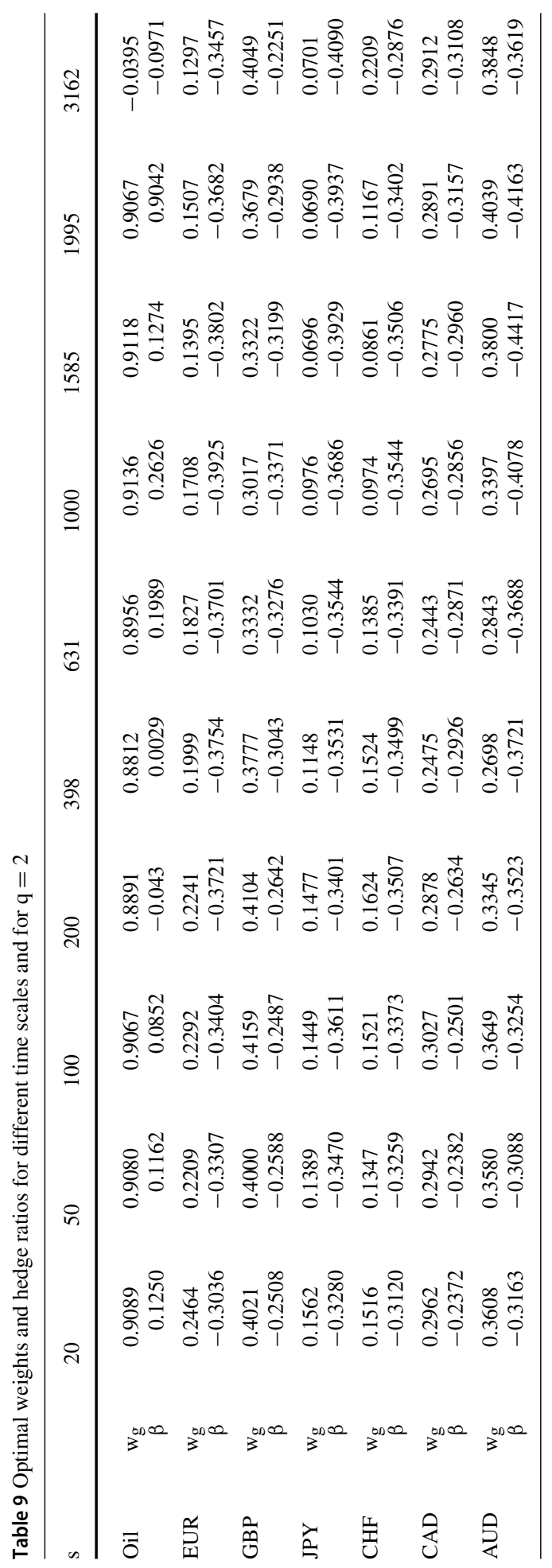




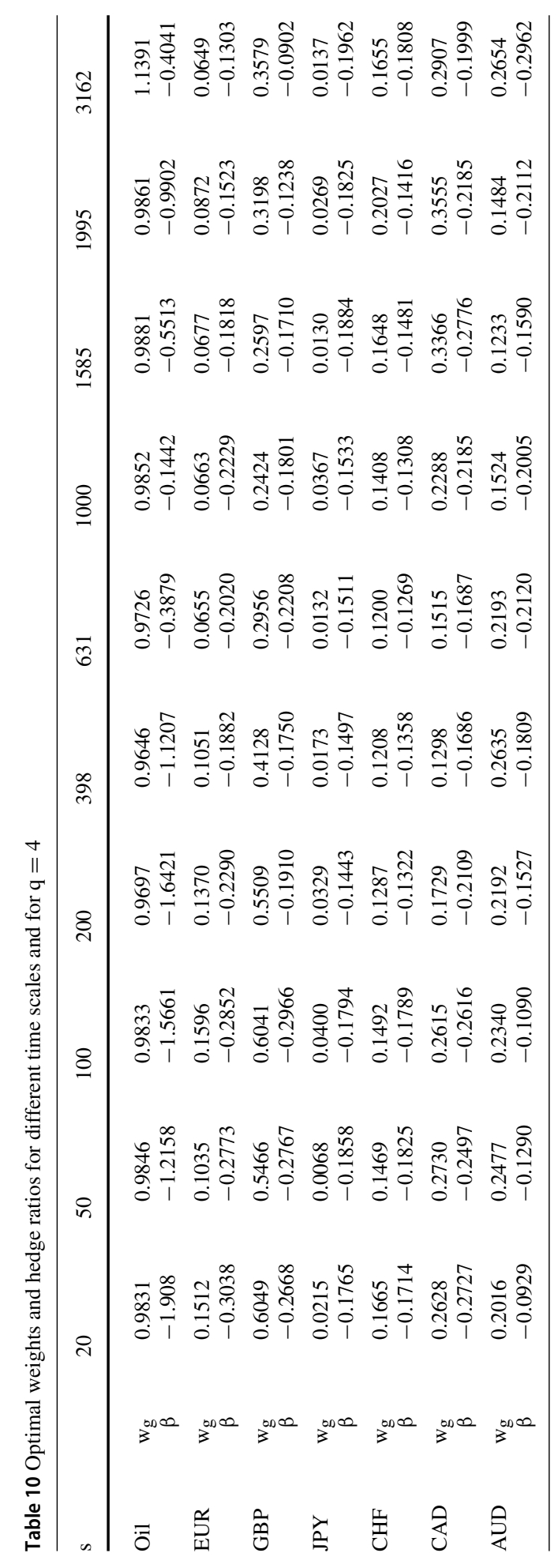


oil and exchange rate risk, especially in less than 1-week trade (for $\mathrm{s}<631$ ), investors should hold more gold assets in turmoil periods in the case of oil and these three currencies.

The yellow metal is commonly considered as one of the most effective hedges or safehaven investment tools, as it has a very low correlation with other assets. Moreover, investing in gold can yield certain commission and tax advantages; the front-end load or commission for derivatives (mainly futures or options) is usually lower than the commission loaded on spot markets and investing in gold futures offers eligibility for the well-known 60/40 tax rule. In other words, regardless of the investment result on a gold futures contract, taxation is treated as $60 \%$ long-term capital gains and $40 \%$ short-term capital gains, which provides an effective tax rate lower than the ordinary income rate.

Based on the economic theories usually grounded on inverse relationships between gold-oil and gold-US exchange rates, we aim to clarify the non-linearity that exists in these relationships based on an original multifractal approach. This study is related to the literature which examines the role of gold as a hedge or safe-haven asset. Recently, Huynh et al. (2020a) and Huynh et al. (2020b) employed the transfer entropy to analyze informational linkage among cryptocurrency markets and gold (and oil), respectively. They argued that investors should conduct portfolio rebalancing by including gold (cryptocurrency) to hedge against the unexpected movement in the cryptocurrency (oil) market. Furthermore, Thampanya et al. (2020) used the linear and non-linear Autoregressive Distributed Lag (ARDL) framework to investigate the hedging effectiveness of gold and bitcoin for equities. Their results reveal that the effects of gold on the stock market are asymmetric in most of the cases. Our approach outperforms the existing techniques employed previously and gives at least two advantages by considering heterogeneity in the horizons of investors and by simultaneously measuring the dependences across tranquil and turmoil market conditions.

Our empirical results yield some interesting implications for investors, financial institutions, and policymakers. First, there is evidence of non-linear relationships among gold, oil, and currencies, which are affected by long memory and fat-tailed distribution. These findings provide comprehensive knowledge of integration among gold and the other two markets, and a clearer view for investors to develop profitable strategies. Second, the linkage between gold and oil prices is insignificant under normal market conditions. Nevertheless, there is a negative and significant relationship between gold and oil under exceptional market circumstances but only in the short term, precisely during the last year of 2018 (see Fig. 4a); after US President Donald Trump's threat of sanctions against Iran (OPEC's third-largest oil producer), the constantly increasing global demand, and the deteriorating situation in Venezuela. These three reasons explain why the price of crude oil rose to USD 76.90. However, in the same period, a trade war between the US and China led to the cessation of Chinese imports of US oil. This deterioration in imports (less than BPD 500,000) hurt US oil producers and led to a large increase in stocks in the US. This largely contributed to a large drop in crude oil below USD 45 at the end of 2018. Thus, the direction of the linkage between gold and oil changes in extreme conditions, resulting in profitable situations of holding gold and oil commodities when performing portfolio diversification. Therefore, traders and portfolio managers should carefully monitor their oil and gold portfolio in such situations. Finally, our results reveal that there is a significant negative relationship between gold prices and the USD for all time scales. Contrarily, this suggests, that when a loss is caused by a depreciating USD, traders and investors could earn profits from the increase in the price of gold. However, investors of origin other than those in the US should act with other hedging strategies so as not to take on exchange rate risk and deterioration in the price of gold and consequently, destruction of their portfolio. Some macro-prudential policies should be adopted by policymakers, particularly in emerging countries, whose currencies are susceptible to shocks that affect international 
trade and capital flows due to the fragility of their economic and financial systems as well as their significant external debt.

Overall, our results on the usefulness of gold as a hedge and safe haven at different investment horizons favor the benefits of including gold futures in oil futures and currency portfolios for risk management purposes. However, the size of those benefits varies by investment horizon according to specific kinds of portfolios, namely, those whose portfolio diversification and hedging ratios were optimally determined.

\section{Conclusion}

We complete the previous studies dealing with gold's role in the financial market, especially with currency and oil markets. Our study offers valuable insights on the role played by the gold market during calm and extreme periods by using intraday data and multifractal method considering the heterogeneity of investors.

Our results provided evidence of negative and significant average and tail dependence for all time scales between gold and USD exchange rates, which is consistent with the role of gold as an effective hedge and safe-haven asset. Furthermore, the evidence of average independence for all time scales and negative and significant tail dependence between gold and oil for short time scales indicated that gold can be used by investors as a weak hedge and as an effective short-term safe-haven asset under exceptional market circumstances. The results of the time-varying dependence also show that gold offers intraday hedging and safehaven benefits to investors at specific periods of time. The role of gold as a hedge and safe haven is pronounced for the case of currency market movements.

Extending our analysis to the optimal hedging strategies between gold, currency, and oil markets, evidence shows that, to reduce risk for different investment horizons, investors should add gold to their portfolios without lowering the anticipated returns of their portfolios.

Funding None.

\section{Declarations}

Conflict of interest The authors declare no conflicts of interest.

Author contributions All authors contributed to the study conception and design. Material preparation and data collection were performed by [Arbi Madani]. The first draft of the manuscript was written by [Arbi Madani] and [Zied Ftiti]. The revised version are prepared by [Arbi Madani] and [Zied Ftiti]. All authors commented on previous versions of the manuscript. All authors read and approved the final manuscript.

\section{Appendix 1}

See Fig. 5. 

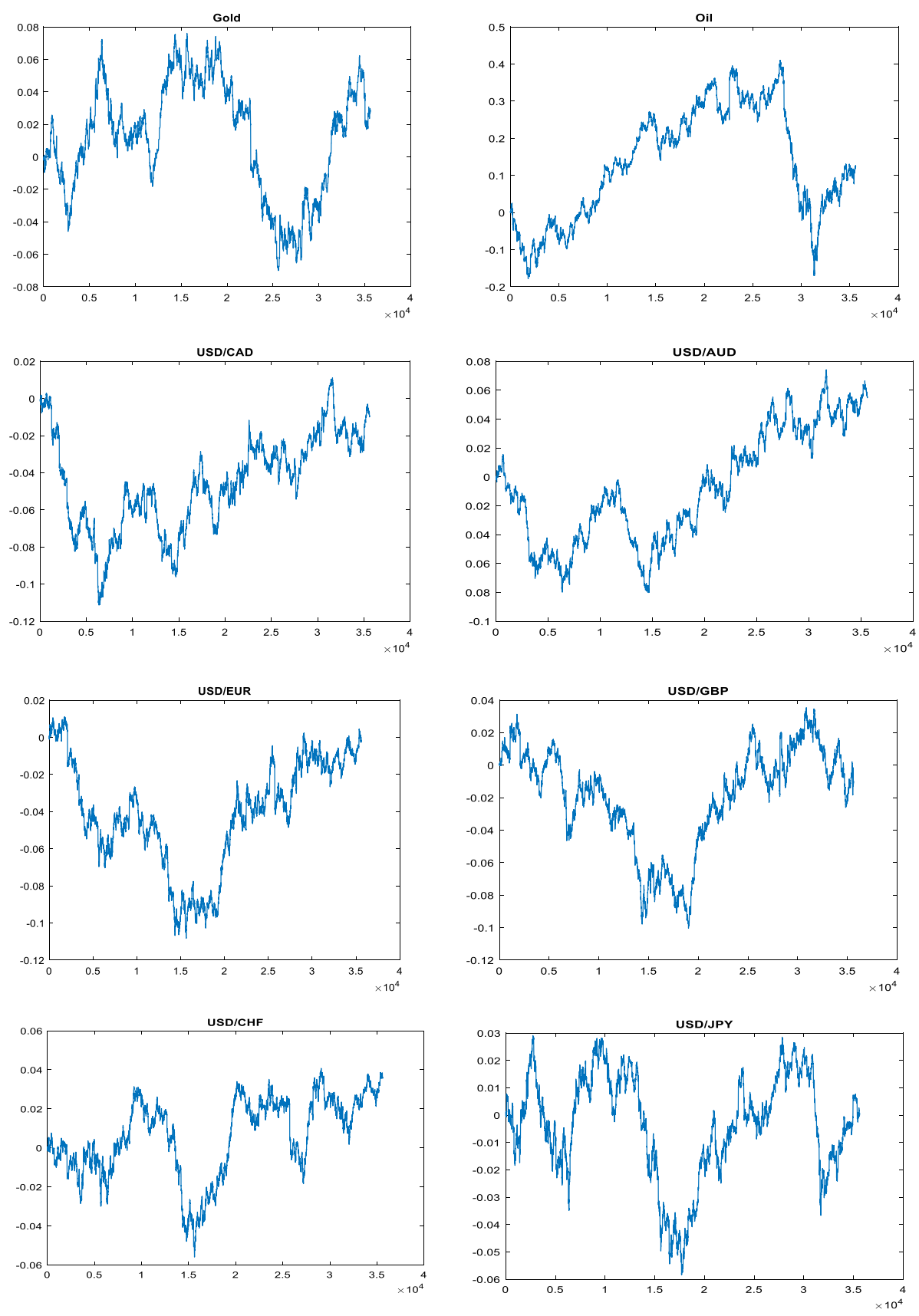

Fig. 5 The cumulative sum of the return series 


\section{Appendix 2}

Proof of the specification of the q-DMCA coefficient.

Based on Kwapien et al. (2015), we present the proof of the specification of the q-DMCA coefficient as follows.

For $q \geq 0$, we have $-1 \leq \rho_{q} \leq 1$, according to the Cauchy-Schwarz-like inequality. According to the relation $2 a^{\alpha} b^{\alpha} \leq a^{2 \alpha}+b^{2 \alpha}$ and for any two parts $v$ and $\mu$,

$$
\begin{gathered}
{\left[F_{X Y}^{q}(s)\right]^{2}=\frac{1}{4 N_{s}^{2}}\left\{\sum_{\nu=0}^{2 N_{s}-1}\left[f_{X Y}^{2}(s, v)\right]^{\frac{q}{2}}\right\}^{2}} \\
\leq \frac{1}{4 N_{s}^{2}} \sum_{\nu=0}^{2 N_{s}-1}\left[f_{X X}^{2}(s, v) f_{Y Y}^{2}(s, v)\right]^{\frac{q}{2}} \\
+\frac{1}{4 N_{s}^{2}} \sum_{\nu=0}^{2 N_{s}-1} \sum_{\mu=v+1}^{2 N_{s}-1}\left\{\left[f_{X X}^{2}(s, v) f_{Y Y}^{2}(s, \mu)\right]^{\frac{q}{2}}+\left[f_{X X}^{2}(s, \mu) f_{Y Y}^{2}(s, v)\right]^{q / 2}\right\} \\
=\frac{1}{4 N_{s}^{2}} \sum_{\nu=0}^{2 N_{s}-1} \sum_{\mu=0}^{2 N_{s}-1}\left[f_{X X}^{2}(s, v) f_{Y Y}^{2}(s, \mu)\right]^{q / 2}=F_{X X}^{q}(s) F_{Y Y}^{q}(s)
\end{gathered}
$$

Thus, $\left[F_{X Y}^{q}(s)\right]^{2} \leq F_{X X}^{q}(s) F_{Y Y}^{q}(s)$, For $q \geq 0$.

For $q<0$, the implication $|a| \leq|b| \Rightarrow|a|^{q} \leq|b|^{q}$ is false and the values of $\rho_{q}(s)$ may arbitrarily converge to large positive or large negative values: $\left|\rho_{q}(s)\right| \gg 1$ for some scales $s$. This case may be viewed as an indicator of a lack of cross-correlations. In other words, the denominator in Eq. (11) may be arbitrarily small compared to the numerator modulus. This situation can occur only when the two series are uncorrelated or weakly correlated.

One of the ways to overcome this problem, as discussed in Kwapien et al. (2015), is to redefine Eq. (11) in the following way:

$$
\rho_{q}^{*}(s)=\left\{\begin{array}{c}
\rho_{q}(s) \text { if }\left|\rho_{q}(s)\right| \leq 1 \\
\frac{1}{\rho_{q}(s)} \text { if }\left|\rho_{q}(s)\right|
\end{array}>1\right.
$$

\section{References}

Alessio, E., Carbone, A., Castelli, G., \& Frappietro, V. (2002). Second-order moving average and scaling of stochastic time series. The European Physical Journal B, 27, 197-200.

Ang, A. G., \& Bekaert, G. (2002). International asset allocation with regime shifts. The Review of Financial Studies, 15, 1137-1187.

Arianos, S., \& Carbone, A. (2007). Detrending moving average algorithm: A closed-form approximation of the scaling law. Physica a: Statistical Mechanics and Its Applications, 382, 9-15.

Barnett, W. A., Liu, J., Mattson, R. S., \& van den Noort, J. (2013). The new CFS Divisia monetary aggregates: Design, construction, and data sources. Open Economies Review, 24(1), 101-124.

Baruník, J., Kočenda, E., \& Vácha, L. (2016). Gold, oil, and stocks: Dynamic correlations. International Review of Economics and Finance, 42, 186-201.

Baur, D. G., \& Lucey, B. M. (2010). Is gold a hedge or a safe haven? An analysis of stocks, bonds, and gold. Financial Review, 45, 217-229.

Baur, D. G., \& McDermott, T. K. (2010). Is gold a safe haven? International evidence. Journal of Banking \& Finance, 34(8), 1886-1898.

Baur, D. G., \& McDermott, T. K. (2016). Why is gold a safe haven? Journal of Behavioral and Experimental Finance, 10, 63-71. 
Beckers, S., \& Soenen, L. (1984). Gold: More attractive to non-U.S. than to U.S. investors? Journal of Business Finance \& Accounting, 11, 107-112.

Beckmann, J., Berger, T., \& Czudaj, R. (2015). Does gold act as a hedge or a safe haven for stocks? A smooth transition approach. Economic Modelling, 48, 16-24.

Beckmann, J., Berger, T., \& Czudaj, R. (2019). Gold price dynamics and the role of uncertainty. Quantitative Finance, 19, 663-681.

Blose, L. E. (2010). Gold prices, cost of carry, and expected inflation. Journal of Economics and Business, $62(1), 35-47$.

Bollerslev, T., Engle, R. F., \& Wooldridge, J. M. (1988). A capital asset pricing model with time varying covariances. Journal of Political Economy, 96, 116-131.

Bouri, E., Jain, A., Biswal, P. C., \& Roubaud, D. (2017). Cointegration and nonlinear causality amongst gold, oil, and the Indian stock market: Evidence from implied volatility indices. Resources Policy, 52, 201-206.

Cajueiro, D. O., \& Tabak, B. M. (2004). The Hurst exponent over time: Testing the assertion that emerging markets are becoming more efficient. Physica a: Statistical Mechanics and Its Applications, 336(3-4), 521-537.

Campbell, J. Y., Hilscher, J., \& Szilagyi, J. (2008). In search of distress risk. The Journal of Finance, 63, 2899-2939.

Chang, H. F., Huang, L. C., \& Chin, M. C. (2013). Interactive relationships between crude oil prices, gold prices, and the NT-US dollar exchange rate-A Taiwan study. Energy Policy, 63, 441-448.

Engle, R. F., \& Granger, C. W. J. (1987). Co-integration and error correction: Representation, estimation, and testing. Economics, 55, 251-276.

Engle, R.F., Granger, C.W.J. (1991). Long-Run Economic Relationships: Readings in Cointegration. Oxford University Press.

Forbes, R., \& Rigobon, R. (2002). No contagion, only interdependence: Measuring stock market comovements. The Journal of Finance, 57(5), 2223-2261.

Ftiti, Z., Guesmi, K., \& Abid, I. (2016). Oil price and stock market co-movement: What can we learn from time-scale approaches? International Review of Financial Analysis, 46, 266-280.

Ftiti, Z., Jawadi, F., Louhichi, W., \& Madani, M. A. (2019). On the relationship between energy returns and trading volume: A multifractal analysis. Applied Economics, 51(29), 3122-3136.

Galton, F. (1886). Regression towards mediocrity in hereditary stature. The Journal of the Anthropological Institute of Great Britain and Ireland, 15, 246-263.

Goodell, J. W. (2020). COVID-19 and finance: Agendas for future research. Finance Research Letters, 35 , 101512.

Gu, G. F., \& Zhou, W. X. (2010). Detrending moving average algorithm for multifractals. Physical Review E, $82(1), 011136$.

Halsey, T. C., Meakin, P., \& Procaccia, I. (1986). Scaling structure of the surface layer of diffusion-limited aggregates. Physical Review Letters, 56, 854.

Hammoudeh, S., \& Yuan, Y. (2008). Metal volatility in presence of oil and interest rate shocks. Energy Economics, 30(2), 606-620.

Hoang, T. H. V., Lahiani, A., \& Heller, D. (2016). Is gold a hedge against inflation? New evidence from a nonlinear ARDL approach. Economic Modelling, 54, 54-66.

Hsieh, D. A. (1991). Chaos and nonlinear dynamics: Application to financial markets. The Journal of Finance, 46(5), 1839-1877.

Huang, H., Huang, T., Chen, X., \& Qian, C. (2013). Exponential stabilization of delayed recurrent neural networks: A state estimation- based approach. Neural Networks, 48, 153-157.

Hull, J. (2011). Fundamentals of Futures and Options Markets. Prentice Hall.

Huynh, T. L. D., Nasir, M. A., Vo, X. V., \& Nguyen, T. T. (2020a). "Small things matter most": The spillover effects in the cryptocurrency market and gold as a silver bullet. The North American Journal of Economics and Finance, 54, 101277.

Huynh, T. L. D., Shahbaz, M., Nasir, M. A., Ullah, S. (2020b). Financial modelling, risk management of energy instruments and the role of cryptocurrencies. Annals of Operations Research, 1-29.

Iqbal, J. (2017). Does gold hedge stock market, inflation, and exchange rate risks? An econometric investigation. International Review of Economics and Finance, 48, 1-17.

Jiang, Z. Q., \& Zhou, W.Z. (2011). Multifractal detrending moving average cross-correlation analysis. Physical Review E, 84(1), 016106.

Joy, M. (2011). Gold and the US dollar: Hedge or haven? Finance Research Letters, 8(3), 120-131.

Kanjilal, K., \& Ghosh, S. (2017). Dynamics of crude oil and gold price post 2008 global financial crisis-New evidence from threshold vector error-correction model. Resources Policy, 52, 358-365.

Kaul, A., \& Sapp, S. (2006). Y2K fears and safe haven trading of the US dollar. Journal of International Money and Finance, 25(5), 760-779. 
Krishan, C., Petkova, R., \& Ritchken, P. (2009). Correlation risk. Journal of Empirical Finance, 16(3), 353-367.

Kristoufek, L. (2013). Mixed-correlated ARFIMA processes for power-law cross-correlations. Physica a: Statistical Mechanics and Its Applications, 392(24), 6484-6493.

Kristoufek, L. (2014a). Measuring correlations between non-stationary series with DCCA coefficient. Physica a: Statistical Mechanics and Its Applications., 402, 291-298.

Kristoufek, L. (2014b). Detrending moving-average cross-correlation coefficient: Measuring crosscorrelations between non-stationary series. Physica a: Statistical Mechanics and Its Applications, 406, 169-175.

Kristoufek, L. (2017). Fractal approach towards power-law coherency to measure cross-correlations between time series. Communications in Nonlinear Science and Numerical Simulation, 50, 193-200.

Kroner, K. F., \& Ng, V. K. (1998). Modeling asymmetric co-movements of asset returns. The Review of Financial Studies, 11(4), 817-844.

Kroner, K. F., \& Sultan, J. (1993). Time-varying distributions and dynamic hedging with foreign currency futures. Journal of Financial and Quantitative Analysis, 28(4), 535-551.

Kumar, S. (2017). On the nonlinear relation between crude oil and gold. Resources Policy, 51, 219-224.

Kwapień, J., Oświęcimka, P., \& Drożdż, S. (2015). Detrended fluctuation analysis made flexible to detect range of cross-correlated fluctuations. Physical Review E, 92, 052815.

Lescaroux, F. (2009). On the excess co-movement of commodity prices-A note about the role of fundamental factors in short-run dynamics. Energy Policy, 37(10), 3906-3913.

Lucey, B. M., Sharma, S. S., \& Vigne, S. A. (2017). Gold and inflation(s): A time-varying relationship. Economic Modelling, 67, 88-101.

Madani, M. A., Ftiti, Z., Louhichi, W., \& Ben Ameur, H. (2020). Intraday hedging and the safe haven role of Bitcoin. Bankers, Markets \& Investors, 163, 2-13.

Markowitz, H. (1952). Portfolio selection. The Journal of Finance, 7, 77-91.

Miyazaki, T., Toyoshima, Y., \& Hamori, S. (2012). Exploring the dynamic interdependence between gold and other financial markets. Economic Bulletin, 32, 37-50.

Narayan, P. K., Narayan, S., \& Zheng, X. (2010). Gold and oil futures markets: Are markets efficient? Applied Energy, 87(10), 3299-3303.

Nguyen, C., Bhatti, M. I., Komorníková, M., \& Komorník, J. (2016). Gold price and stock markets nexus under mixed-copulas. Economic Modelling, 58, 283-292.

Nguyen, D. K., Sensoy, A., Sousa, R. M., \& Uddin, G. S. (2020). US equity and commodity futures markets: Hedging or financialization? Energy Economics, 86, 104660.

Oświęcimka, P., Drożdż, S., Forczek, M., Jadach, S., Kwapień, J. . (2014). Detrended cross correlation analysis consistently extended to multifractality. Physical Review E, 89(2), 023305.

Pearson, K. (1895). Mathematical contributions to the theory of evolution. III. Regression, heredity, and panmixia. Philosophical Transactions A, 373, 253-318.

Peng, C. K., Havlin, S., Stanley, H. E., \& Goldberger, A. L. (1995). Quantification of scaling exponents and crossover phenomena in nonstationary heartbeat time series. Chaos, 5, 82-87.

Piao, L., \& Fu, Z. (2016). Quantifying distinct associations on different temporal scales: Comparison of DCCA and Pearson methods. Science and Reports, 6(1), 36759. https://doi.org/10.1038/srep36759

Plerou, V., Gopikrishnan, P., Rosenow, B., Amaral, L. A. N., Guhr, T., \& Stanley, H. E. (2002). Random matrix approach to cross correlations in financial data. Physical Review E, 65(6), 066126.

Podobnik, B., \& Stanley, H. E. (2008). Detrended cross-correlation analysis: A new method for analyzing two non-stationary time series. Physical Review Letters, 100, 84-102.

Reboredo, J. C. (2013). Is gold a safe haven or a hedge for the US dollar? Implications for risk management. Journal of Banking \& Finance, 37, 2665-2676.

Reboredo, J. C., \& Rivera-Castro, M. A. (2014a). Can gold hedge and preserve value when the US dollar depreciates? Economic Modelling, 39, 168-173.

Reboredo, J. C., \& Rivera-Castro, M. A. (2014b). Gold and exchange rates: Downside risk and hedging at different investment horizons. International Review of Economics and Finance, 34, 267-279.

Rodgers, J. L., \& Nicewander, W. A. (1988). Thirteen ways to look at the correlation coefficient. American Statistician, 42(1), 59-66.

Schreiber, T., \& Schmitz, A. (1996). Improved surrogate data for nonlinearity tests. Physical Review Letters, 77(4), 635-638.

Sephton, P., \& Mann, J. (2018). Gold and crude oil prices after the great moderation. Energy Economics, 71, $273-281$.

Shao, Y. H., Gu, G. F., Jiang, Z. Q., Zhou, W. W., \& Sornette, D. (2012). Comparing the performance of FA, DFA and DMA using different synthetic long-range correlated time series. Science and Reports, 2, 835. Sjaastad, L. A. (2008). The price of gold and the exchange rates: Once again. Resources Policy, 33, 118-124. 
Sjaastad, L. A., \& Scacciavillani, F. (1996). The price of gold and the exchange rate. Journal of International Money and Finance, 15, 879-897.

Sun, X., \& Liu, Z. (2016). Optimal portfolio strategy with cross-correlation matrix composed by DCCA coefficients: Evidence from the Chinese stock market. Physica a: Statistical Mechanics and Its Applications, 444, 667-679.

Thampanya, N., Nasir, M. A., \& Huynh, T. L. D. (2020). Asymmetric correlation and hedging effectiveness of gold \& cryptocurrencies: From pre-industrial to the 4th industrial revolution. Technological Forecasting and Social Change, 159, 120195.

Tiwari, A. K., Aye, G. C., Gupta, R., Gkillas, K. (2020). Gold-oil dependence dynamics and the role of geopolitical risks: Evidence from a Markov-switching time-varying copula model. Energy Economics. 104748.

Tully, E., \& Lucey, B. (2007). A power GARCH examination of the gold market. Research in International Business and Finance, 21(2), 316-325.

Vandewalle, N., \& Ausloos, M. (1998). Crossing of two mobile averages: A method for measuring the roughness exponent. Physical Review E, 58, 6832-6834.

Wang, K. M., Lee, Y. M., \& Nguyen Thi, T. B. (2011). Time and place where gold acts as an inflation hedge: An application of long-run and short-run threshold model. Economic Modelling, 28(3), 806-819.

Wạtorek, M., Drożdż, S., Oświęcimka, P., Stanuszek, M., . (2019). Multifractal cross-correlations between the world oil and other financial markets in 2012-2017. Energy Economics, 81, 874-885.

Xu, L., Ivanov, P. C., Hu, K., Chen, Z., Carbone, A., \& Stanley, H. E. (2005). Quantifying signals with powerlaw correlations: A comparative study of detrended fluctuation analysis and detrended moving average techniques. Physical Review E, 71(5), 051101.

Ye, Y. (2007). Analysis on linkage between gold price and oil price. Gold, 28, 4-7.

Zebende, G. F. (2011). DCCA cross-correlation coefficient: Quantifying level of cross-correlation. Physica a: Statistical Mechanics and Its Applications, 390, 614-618.

Zhang, Y., Xu, L., \& Chen, H. M. (2007). An empirical study on the relationship between prices of petroleum and gold industry. Res. Financ. Econ. Issues, 7, 35-39.

Zhou, W. X., Sornette, D., \& Yuan, W. K. (2006). Inverse statistics and multifractality of exit distances in 3D fully developed turbulence. Physica D Nonlinear Phenomena, 214(1), 55-62.

Publisher's Note Springer Nature remains neutral with regard to jurisdictional claims in published maps and institutional affiliations. 